\title{
REGENERAÇÃO DA COBERTURA VEGETAL EM ÁREA DE AGRICULTURA DE CORTE E QUEIMA EM SÃO PEDRO DA SERRA, NOVA FRIBURGO (RIO DE JANEIRO, BRASIL)
}

\author{
REGENERATION OF VEGETATION COVER IN AN AREA FORMERLY SUBJECT TO SLASH AND \\ BURN AGRICULTURE IN SÃO PEDRO DA SERRA, NOVA FRIBURGO (RIO DE JANEIRO, BRAZIL)
}

Karla Karina Santos da Costa ${ }^{\mathbf{A}}$

Ana Valéria Freire Allemão Bertolino ${ }^{\mathrm{A}}$

iD Ana Angélica Monteiro de Barros ${ }^{\mathrm{A}}$

${ }^{\text {A }}$ Universidade do Estado do Rio de Janeiro (UERJ-FFP), São Gonçalo, RJ, Brasil

Recebido em: 08/03/2021 | 11/06/2021 DOI: 10.12957/tamoios.2021.58517

Correspondência para: Ana Valéria Freire Allemão Bertolino (anabertolino@uol.com.br)

\begin{abstract}
Resumo
A agricultura tradicional de corte e queima é praticada há muito tempo nas áreas florestadas, principalmente em ambientes tropicais. Com a finalidade de avaliar a regeneração da cobertura vegetal após período de pousio de 4 a 7 anos (PO I), de 10 a 12 anos (PO II) e uma área controle florestal com 50 a 70 anos (FL) foram desenvolvidos estudos de fitossociologia da vegetação em uma área experimental em São Pedro da Serra, região serrana do estado do Rio de Janeiro. Foram implantadas três parcelas longitudinais totalizando uma área amostral de $600 \mathrm{~m}^{2}$ em cada sistema. A amostragem englobou plantas arbóreas e arbustivas com $\mathrm{DAP} \geq 5,0 \mathrm{~cm}$, que foram coletadas para posterior identificação. Os resultados sugerem que os sistemas PO I e PO II encontram-se em estágio inicial de regeneração. FL apresenta na sua maioria espécies secundárias iniciais e tardias. As espécies que foram mais representativas nos sistemas foram Machaerium stipitatum Vogel e Palicourea sessilis (Vell.) C.M. Taylor, ambas comuns em áreas degradadas. As famílias com maior valor de importância foram Euphorbiaceae em PO I, Leguminosae em PO II e Rubiaceae em FL, que de acordo com outros estudos, são as que mais contribuem com espécies na Mata Atlântica na região Sudeste.
\end{abstract}

Palavras-chave: Pousio; Agricultura de corte e queima; Fitossociologia; Florística; Mata Atlântica.

\begin{abstract}
Traditional slash-and-burn agriculture has long been practiced in forested areas, especially in tropical environments. In order to evaluate the regeneration of the vegetation cover after a fallow period of 4 to 7 years (PO I), 10 to 12 years (PO II) and a forest control area with 50 to 70 years (FL), studies of phytosociology of vegetation in an experimental area in São Pedro da Serra, mountain region of the state of Rio de Janeiro. Three longitudinal plots were implanted, totaling a sample area of 600 $\mathrm{m}^{2}$ in each system. Sampling included tree and shrub plants with $\mathrm{DAP} \geq 5.0 \mathrm{~cm}$, which were collected for later identification. The results suggest that the PO I and PO II systems are in an initial stage of regeneration. FL mostly presents early and late secondary species. The species that were most representative in the systems were Machaerium stipitatum Vogel and Palicourea sessilis (Vell.) C.M. Taylor, both common in degraded areas. The most important families were Euphorbiaceae in PO I, Leguminosae in PO II and Rubiaceae in FL, which, according to other studies, are the ones that most contribute to species in the Atlantic Forest in the Southeast.
\end{abstract}

Keywords: Fallow; slash-and-burn agriculture; Phytosociology; Floristics; Atlantic Forest. 


\section{INTRODUÇÃO}

Os termos shifting agriculture e slash-and-burn envolvem uma série de técnicas que denotam seu caráter diversificado em diferentes partes do mundo. Entretanto, tem como característica similar o aproveitamento do capital energético da floresta em regeneração. Mesmo com muitas variantes, as características essenciais do padrão de cultivo nestes sistemas são a utilização do corte da vegetação, uso do fogo e períodos de pousio da terra após a colheita (PEDROSO JUNIOR; MURRIETA; ADAMS, 2008). Sanchez et al. (2005) demonstram que esses sistemas distintos apresentam atributos peculiares. O primeiro está associado à rotação tradicional de culturas agrícolas com longos períodos de pousio e o segundo com curtos períodos.

No presente estudo foi adotado o slash-and-burn, embora seja um tipo de sistema de manejo muito criticado por vários autores (CHIDUMAYO; KWIBISA, 2003; MACDONALD et al., 2000, LAWRENCE et al., 2007). No entanto, permite a regeneração natural das áreas utilizadas para plantios a partir do pousio, atestando sua sustentabilidade quando praticado tradicionalmente (FRIZANO et al., 2003; JOHNSON et al., 2001; PÉREZ-CABELLO et al., 2003; NIGH; DIEMONT, 2013).

Um dos problemas relacionados ao sistema slash-and-burn é a redução do tempo de pousio (BORGGAARD; GAFUR; PETERSEN, 2003; LAWRENCE et al., 2007; STYGER et al., 2007). Outro aspecto é a utilização do fogo, que pode trazer modificações nas propriedades do solo (CERTINI, 2005; MATAIX-SOLERA et al., 2011), repelência da água (DEBANO, 2000), escoamento superficial (CERDÁ; LASANTA, 2005) e perda de nutrientes (LAWRENCE et al., 2007). Por outro lado, o slash-and-burn também foi analisado por diferentes autores que constataram a melhoria do sistema em relação à recarga e drenagem dos solos (ERREA et al., 2001), aumento dos macroagregados (OBALE-EBANGA et al., 2003) e diminuição da erosão e escoamento superficial (THOMAZ, 2013).

O sistema de pousio mantém a sustentabilidade ambiental da exploração agrícola ao longo do tempo, já que os processos erosivos são minimizados, se adaptando à grande maioria dos solos de regiões tropicais, que geralmente não são muito férteis ou possuem deficiências de determinados nutrientes (ADAMS, 2000). Nas regiões de vertentes íngremes e relevo movimentado, por exemplo, é uma das práticas mais adaptadas para pequenas propriedades agrícolas, devido aos baixos níveis de insumos e elevada disponibilidade de mão-de-obra.

Gomez-Pompa (1992) discute que as populações nativas do Brasil já manipulavam os ambientes através de técnicas agrícolas como a do pousio. Esses sistemas resultavam na maior diversidade de espécies em habitats manipulados do que nas florestas consideradas nativas. Esse fato é corroborado por Balée (1993), que afirma que num ecossistema manejado na 
Amazônia brasileira, algumas espécies podem se extinguir como resultado dessa ação, ainda que o efeito total dessa interferência possa resultar num aumento real da diversidade ecológica e biológica de um lugar específico ou região.

Nesse contexto, entender a sucessão ecológica como um processo linear, onde a vegetação atinge um estágio sucessional estável é um equívoco. É possível ocorrerem múltiplas alternativas, nunca se atingindo um estágio verdadeiramente estável, devido à ocorrência de perturbações diversas (CHRISTENEN, 1988), ainda mais em áreas de agricultura de corte e queima da vegetação (PEDROSO JUNIOR; MURRIETA; ADAMS, 2008). E entender o processo de regeneração da vegetação depende de diversos fatores e, por isso não, é fácil se fazer uma previsão exata.

O conhecimento sobre as características da vegetação e do fogo, bem como o entendimento dos mecanismos que influenciam a resposta das diferentes espécies de plantas em áreas de agricultura de corte e queima constituem fatores chave na gestão de áreas protegidas como em unidades de conservação da natureza (UC) da categoria uso sustentável. Assim, o objetivo deste estudo foi avaliar as transformações na estrutura da vegetação em uma região onde houve a prática de pousio em três áreas com diferentes tempos de descanso e regeneração natural da floresta, com a finalidade de se criar subsídios para o entendimento das paisagens onde se pratica a agricultura de corte e queima.

\section{METODOLOGIA}

\section{Área de Estudo}

São Pedro da Serra é o sétimo Distrito do município de Nova Friburgo, localizado na região serrana do estado do Rio de Janeiro. Ocupa $64,5 \mathrm{~km}^{2}$ de extensão, atingindo cerca de 700 metros de altitude (Figura 1). Encontra-se inserido na Área de Proteção Ambiental (APA) Estadual de Macaé de Cima, que engloba também os distritos de Lumiar e Muri. Essa APA foi criada pelo Decreto Lei Estadual n ${ }^{0} 29.213$ em 14 de setembro de 2001 (RIO DE JANEIRO, 2001), numa área de 35.000 ha. É considerada a segunda maior UC estadual e integra o Corredor Central Fluminense, um mosaico formado por 22 UC que abrangem 13 municípios fluminenses (LINO et al., 2007).

O clima regional é do tipo superúmido $(C f b)$, segundo classificação de Köppen-Geiger (KOTTEK et al., 2006), com temperaturas médias que variam entre $18^{\circ} \mathrm{C}$ no inverno e $24^{\circ} \mathrm{C}$ no verão. $\mathrm{O}$ índice pluviométrico e umidade relativa do ar na região são bastante elevados, com período de chuvas intensas entre os meses de novembro a março (MATOS; FERRARI; CAVALCANTE, 1980). 
Figura 1: Localização do distrito de São Pedro da Serra, município de Nova Friburgo, estado do Rio de Janeiro, Brasil.

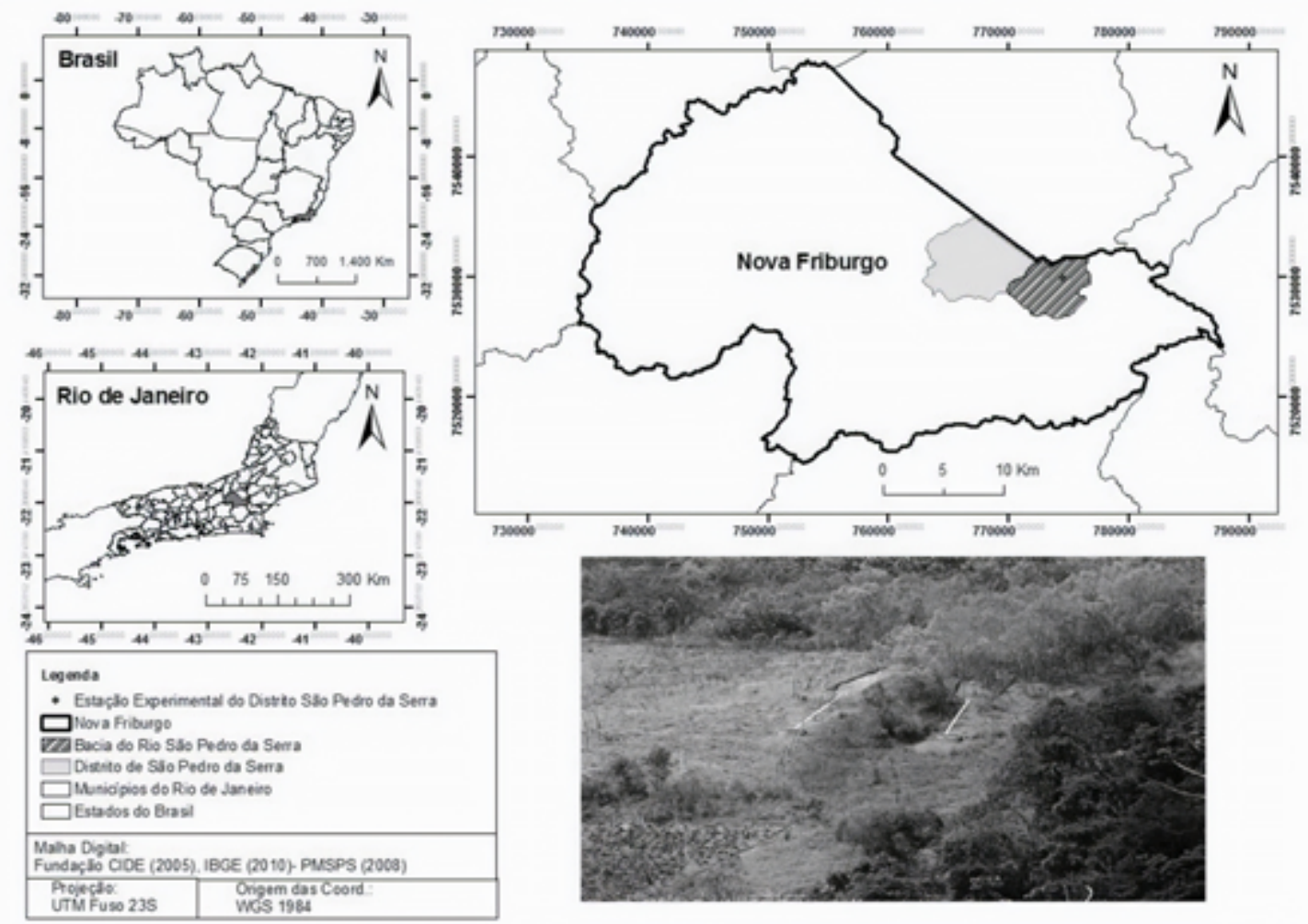

Fonte: Laboratório de Geociências da UERJ/FFP.

A região de Nova Friburgo está inserida na Serra do Mar, na porção pertencente à Faixa Móvel Ribeira, que estruturalmente compreende um complexo cinturão de dobramentos e empurrões de tendência NE-SW. Essa estrutura tem origem na borda Sul/Sudeste do Cráton de São Francisco, a partir da colisão deste com outras placas e/ou microplacas (HEILBRON et al., 2004). Segundo o Mapa Geológico do Estado do Rio de Janeiro (CPRM, 2016) há na APA a ocorrência de uma a unidade denominada São Fidélis. Esta unidade é composta por kinzigito; (cordierita)-(grafita)-(sillimanita) - granada-biotita gnaisse, kinzigito (cordierita)-(sillimanita) - biotita gnaisse bandado, com intercalações de quartzito, rochas 
calcissilicáticas e anfibolitos. O conteúdo litológico da unidade São Fidélis é formado por paragnaisses metapelíticos com camadas ou lentes de outros metassedimentos. A unidade basal do grupo é constituída predominantemente por gnaisse kinzigítico (CPRM, 2016). Essa mesma localidade apresenta-se em dois domínios geomorfológicos: escarpas serranas e domínio montanhoso (DANTAS, 2000).

As principais classes de solos que ocorrem são os Neossolos Litólicos, inseridos em relevo montanhoso/escarpado, Latossolos Vermelho-Amarelos e Cambissolos Háplicos (CARVALHO FILHO et al., 2000), formados a partir de gnaisses biotíticos, kinzigitos e depósitos colúvio-aluvionares. A hidrografia da região de São Pedro da Serra é composta por uma das principais microbacias hidrográficas do município de Nova Friburgo, a bacia hidrográfica do Rio Macaé, que divide os distritos de Lumiar e São Pedro da Serra (MORETT; MAYER, 2003).

A fitofisionomia original é associada ao Domínio da Mata Atlântica, correspondente a Floresta Ombrófila Densa Montana, segundo a classificação de Veloso et al. (1991), atualizada pelo IBGE (2012). Esse tipo de formação florestal se estende da cota de 500 até 1.500 metros de altitude. Representa um importante remanescente da antiga cobertura florestal que se estendia por toda a Serra do Mar, abrigando uma considerável área florestal bem conservada (LIMA; GUEDES BRUNI, 1996). O inventário florístico realizado em Macaé de Cima aponta a presença de 1.103 espécies de plantas vasculares, pertencentes a 413 gêneros e 122 famílias. Esse estudo demonstra a singularidade da flora local devido ao alto percentual de plantas endêmicas da Mata Atlântica do Sudeste brasileiro (LIMA; GUEDES BRUNI, 1997).

A APA de Macaé de Cima abriga trechos de floresta em diferentes estágios sucessionais, principalmente nos vales, onde estão presentes antigos assentamentos de colonos suíços. Nessa região há formações de pastagem e florestas secundárias. Em São Pedro da Serra, a paisagem é composta por áreas em pousio (capoeira) intercaladas com lavouras e vegetação em estágios mais adiantados de regeneração. Observam-se diferentes componentes que incluem encostas montanhosas íngremes, pequenos vales, grotas, áreas ribeirinhas e afloramentos rochosos expostos, com presença de uma vegetação própria desse tipo de ambiente.

Especificamente na área do presente estudo a vegetação na área florestal forma um dossel uniforme, resultante da presença de árvores de grande porte, que dificilmente sobressaem entre si. Na parte mais úmida da floresta ocorrem árvores emergentes que alcançam até $40 \mathrm{~m}$ de altura, incluindo espécies como Miconia cinnamomifolia (DC.) Naudin. (jacatirão) e Cedrela odorata L. (cedro-rosa). O sub-bosque é muito denso e diversificado, recobrindo quase que completamente o solo. Observam-se na vegetação arbustiva Piper eucalyptophyllum C.DC., Leandra melastomoides Raddi, Mollinedia schottiana (Spreng.) Perkins dentre outras, além de espécies exóticas como Coffea arabica L., como resquício de práticas agrícolas pretéritas. $\mathrm{O}$ estrato herbáceo é composto por ervas e espécies subarbustivas, tais como: Coccocypselum lanceolatum (Ruiz et Pavon) Pers. e Caamembeca 
laureola (A. St.-Hil. \& Moq.) J.F.B. Pastore. Espécies epífitas e trepadeiras são também muito abundantes, expressando uma grande riqueza florística. Destacam-se dentre as espécies trepadeiras Davilla rugosa Poir., Reissekia smilacina (Sm.) Steud., Paullinia micrantha Cambess. e Tanaecium selloi (Spreng.) L.G. Lohmann.

\section{Amostragem florística e fitossociológica}

Para a análise da vegetação foi utilizado o método de parcelas (DURIGAN, 2004), implantadas em três diferentes áreas anteriormente desmatadas e queimadas para atividades agrícolas no sistema slash-and-burn, sendo essas posteriormente abandonadas, passando ao processo de regeneração natural em pousio: Pousio I com 4 a 7 anos de regeneração (PO I), Pousio II com 10 a 12 anos (PO II) e Floresta com 50 a 70 anos (FL), uma área de mata mais conservada próxima à cumeeira do morro (Figura 2). $\mathrm{O}$ desenho amostral incluiu três parcelas de 50,0 X 4,0 m com $200 \mathrm{~m}^{2}$ em cada ambiente por se tratarem de áreas pequenas de antigos plantios com datas de abandono conhecidas, totalizando $1.800 \mathrm{~m}^{2} \mathrm{em}$ todo sistema.

Figura 2: Visão geral da área de estudo em São Pedro da Serra, município de Nova Friburgo, estado do Rio de Janeiro, Brasil com a indicação das áreas amostradas e entorno. FL Floresta de 50 a 70 anos; PO I - Pousio I de 4 a 7 anos; PO II - Pousio II de 10 a 12 anos; GR - Área de pasto com capim-gordura (Melinis minutiflora P. Beauv.); PC - Plantio Convencional.

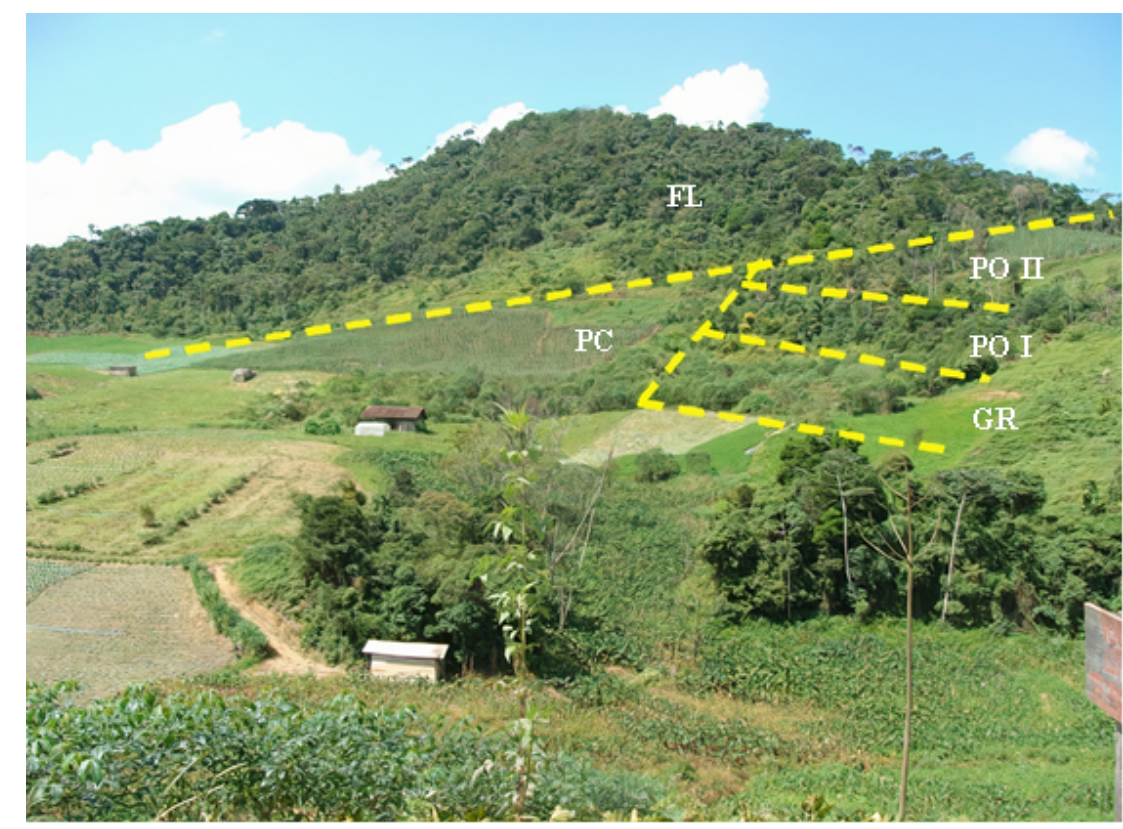

Fonte: Laboratório de Geociências da UERJ/FFP.

O critério de inclusão das plantas considerou espécies arbóreas e arbustivas com diâmetro à altura do peito $(\mathrm{DAP}) \geq 5,0 \mathrm{~cm}$, medido a $1,30 \mathrm{~m}$ do ponto de enraizamento e altura mínima de 2,0 m, estimada com podão de vara articulado, cujo alcance máximo é de $12 \mathrm{~m}$ de altura. Esse critério foi baseado no Decreto Lei Federal n 750/93 (BRASIL, 1993) que proíbe o corte e supressão da vegetação primária e secundária nativa de Mata Atlântica acima desse 
diâmetro. Todos os indivíduos férteis ou não da área de amostragem foram coletados, segundo técnicas usuais utilizadas em inventários florísticos (GUEDES BRUNI et al., 2002).

As amostras de plantas foram herborizadas e secas em estufa a $60^{\circ} \mathrm{C}$ (PEIXOTO; MAIA, 2013), para posteriormente serem identificados através de bibliografia especializada e comparações no acervo digital disponível na base de dados REFLORA Herbário Virtual (REFLORA, 2021), além de consultas aos taxonomistas das famílias, quando necessário. $\mathrm{O}$ material testemunho fértil foi registrado e incorporado aos herbários RFFP e RB. A lista florística foi organizada de acordo com o Angiosperm Phylogeny Group IV (APG IV, 2016), sendo que Leguminosae seguiu a proposta do LPWG (2017). A grafia dos nomes das espécies foi confirmada com auxílio da plataforma digital Flora do Brasil 2020 (REFLORA, 2020). Ao longo do texto, as espécies são citadas sem o nome dos autores, por já constarem na tabela 2.

Os parâmetros fitossociológicos foram calculados no software FITOPAC 2.1 (SHEPHERD, 2009) e incluiu a densidade, dominância, frequência e valor de importância (IVI) das espécies inventariadas (VUONO, 2002; MAGURRAN, 2013). Para avaliação da diversidade foram utilizados os índices de Shannon-Weaver (H') e Simpson (D) (MAGURRAN, 2013). Foram elaborados histogramas de frequência das classes de diâmetro, sendo o intervalo de classe ideal (IC), calculado conforme segundo Spiegel (1970) e Felfili e Silva Júnior (1988).

Quanto ao caráter sucessional foi utilizada a classificação de Gandolfi, Leitão Filho e Bezerra (1995), onde as espécies são categorizadas como pioneiras, secundárias iniciais e secundárias tardias. A classificação baseou-se em observações de campo e consulta a literatura que envolve a discussão sobre dinâmica sucessional (GANDOLF; LEITÃO FILHO; BEZERRA, 1995; SANCHEZ et al., 1999; DISLICH et al., 2001; GUARIGUATA; OSTERTAG, 2001; OLIVEIRA; MANTOVANI; MELO, 2001; OLIVEIRA FILHO et al., 2004; GUARATINI et al., 2008; GRINGS; BRACK, 2009; FERNANDES et al., 2013; MARMONTEL et al., 2013). Foi elaborado o diagrama de Venn com base em Gotelli e Ellison (2026) para mostrar o compartilhamento de espécies entre as áreas avaliadas.

\section{RESULTADOS}

Foi marcado um total de 255 indivíduos, sendo 224 vivos e 31 mortos em pé. Os dados comparativos entre as áreas estudadas são apresentados na tabela 1 . O ambiente de floresta apresentou o maior número de indivíduos marcados, seguidos de PO II e PO I respectivamente. Da mesma forma que em relação ao número de espécies, gêneros e famílias. Três espécies não foram identificadas, outras três foram apenas em nível de família e quatro em gênero.

Tabela 1: Dados comparativos entre as áreas estudadas em relação aos indivíduos amostrados em sistemas de pousios em São Pedro da Serra, município de Nova Friburgo, estado do Rio de Janeiro, Brasil. 


\begin{tabular}{l|c|c|c}
\hline $\begin{array}{c}\text { ÁREAS } \\
\text { AMOSTRADAS }\end{array}$ & $\begin{array}{c}\text { NÚMERO DE } \\
\text { INDIVÍDIOS } \\
\text { MARCADOS }\end{array}$ & $\begin{array}{c}\text { NÚMERO DE } \\
\text { INDIVÍDUOS } \\
\text { VIVOS }\end{array}$ & $\begin{array}{c}\text { NÚMERO DE } \\
\text { INDIVÍDUOS } \\
\text { MORTOS }\end{array}$ \\
\hline $\begin{array}{c}\text { PO I } \\
5 \text { espécies } \\
5 \text { gêneros } \\
5 \text { famílias } \\
2 \text { indeterminadas }\end{array}$ & 30 & & 10 \\
\hline $\begin{array}{c}\text { PO II } \\
7 \text { espécies } \\
5 \text { gêneros } \\
4 \text { famílias, }\end{array}$ & & 20 & \\
\hline $\begin{array}{c}\text { FL } \\
31 \text { espécies } \\
27 \text { gêneros } \\
19 \text { famílias } \\
1 \text { indeterminada }\end{array}$ & 63 & 58 & \\
\hline
\end{tabular}

Fonte: Elaborada pelo autor.

O inventário florístico apontou 38 espécies, distribuídas em 32 gêneros e 20 famílias de Angiospermas (Tabela 2). As famílias mais ricas em espécies foram Leguminosae (7), Salicaceae (4), Rubiaceae e Solanaceae (3, cada). Cinco famílias apresentaram duas espécies cada e onze apenas uma cada. Leguminosae e Rubiaceae mostraram a maior população, com 54 e 45 indivíduos respectivamente, representando 50,5\% do total amostrado. Os resultados confirmam outros estudos realizados na Mata Atlântica do Sudeste brasileiro que apontam essas famílias como as de maior abundância entre as espécies arbóreas (OLIVEIRA FILHO; FONTES, 2000). Na figura 3 é apresentado o gráfico com a distribuição do número de indivíduos por essas famílias nas áreas de pousio avaliadas.

Figura 3: Principais famílias com o maior número de indivíduos presentes nos sistemas de pousio em São Pedro da Serra, município de Nova Friburgo, estado do Rio de Janeiro.

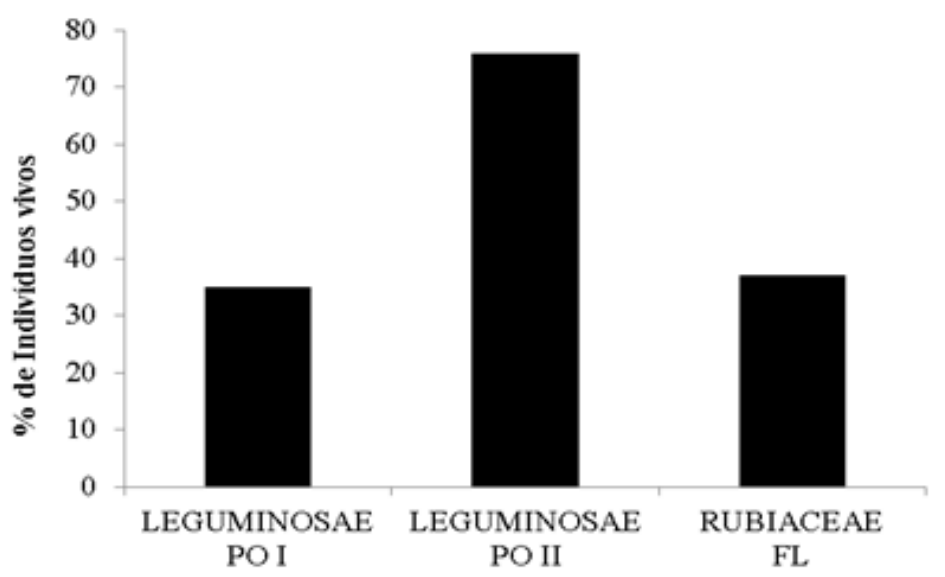

Fonte: Laboratório de Geociências da UERJ/FFP. 
Foi observada uma espécie exótica frutífera em PO I, Persea americana (abacateiro), sendo que as demais têm ocorrência natural na Mata Atlântica. Interessante o registro na área de estudo, tão explorada pela agricultura, de Cedrela odorata (cedro-rosa) em ambiente florestal. Segundo Martinelli e Moraes (2013) essa espécie consta da lista vermelha de plantas ameaçadas de extinção na categoria vulnerável. Trata-se de uma espécie madeireira com alto valor comercial e intensamente explorada. Atualmente teve o declínio de sua população no Brasil a $30 \%$ ao longo de três gerações.

As espécies mais representativas em número de indivíduos foram Palicourea sessilis (45), Machaerium stipitatum (42), Guapira oposita (13), Croton floribundus (10) e Piptadenia gonoachanta (6). Com exceção de Machaerium stipitatum, todas as outras foram listadas por Pessoa, Guedes Bruni e Kurtz. (1997) em um trecho de vegetação secundária estudado por esses autores em Macaé de Cima. Palicourea sessilis consta como a espécie que mais contribuiu em número de indivíduos, após Euterpe edulis, nos inventários estruturais realizados na Floresta Ombrófila Densa de Nova Friburgo. Apresenta grande plasticidade fenotípica, principalmente em relação à idade dos indivíduos, a maior ou menor exposição ao sol e à maior ou menor umidade dos solos onde está estabelecida. Normalmente distribui-se desde Santa Catarina à Bahia, na Floresta Ombrófila Densa Montana, Alto Montana e campo altimontano, em florestas ripárias e campos rupestres (GUEDES BRUNI; LIMA, 1996). Machaerium stipitatum não consta em nenhum estudo florístico realizado na região, pois se trata de uma espécie mais restrita a ambientes muito perturbados. De modo geral, a vegetação de Nova Friburgo, e principalmente da APA de Macaé de Cima, ainda carece de mais trabalhos desse tipo. Principalmente nas áreas mais impactadas, o que poderia servir de subsídios para o delineamento de políticas públicas para a recuperação dos remanescentes florestais em lugares onde se pratica agricultura no sistema slash-and-burn.

Tabela 2: Listagem florística das espécies de Angiospermas inventariadas nos três sistemas de pousio estudados em São Pedro da Serra, município de Nova Friburgo, estado do Rio de Janeiro, Brasil. PO I - Pousio de 4 a 7 anos; PO II - Pousio de 10 a 12 anos; FL - Floresta de 50 a 70 anos. PI - Pioneira; SI - Secundária Inicial; ST - Secundária Tardia; SC - Sem Classificação. * Espécies não encontradas férteis.

\begin{tabular}{lcccccc}
\hline \multicolumn{1}{c}{ Família/Espécie } & $\begin{array}{c}\text { Nome } \\
\text { Vernacular }\end{array}$ & $\begin{array}{c}\text { P } \\
\text { O }\end{array}$ & $\begin{array}{c}\text { PO } \\
\text { II }\end{array}$ & FL & $\begin{array}{c}\text { Estágio } \\
\text { Sucessional }\end{array}$ & Voucher \\
\hline Annonaceae & & & & & & \\
$\quad \begin{array}{l}\text { Annona sylvatica A. St.-Hil. } \\
\text { Xylopia brasiliensis Spreng. }\end{array}$ & araticum & & $\mathrm{X}$ & $\mathrm{ST}$ & $*$ \\
\hline Apocynaceae & pindaíba & & $\mathrm{X}$ & $\mathrm{PI}$ & $*$ \\
$\quad$ Apocynaceae 1 & - & & & & SC & K.K.S.Costa 02 \\
\hline
\end{tabular}

Asteraceae 
Piptocarpha macropoda (DC.) canela-branca $\quad$ X $\quad$ SI *

Baker

$\begin{array}{llllll}\text { Vernonanthura polyanthes } & \text { assa-peixe } & \mathrm{X} & \mathrm{X} & & \text { PI }\end{array}$

(Sprengel) Vega \& Dematteis

Bignoniaceae

Sparattosperma leucanthum

caroba-branc

X SI

(Vell.) K. Schum.

\section{Euphorbiaceae}

Croton floribundus Spreng.

a

\section{Lacistemataceae}

Lacistema pubescens Mart.

capixingui $\mathrm{X}$

X PI

$*$

\section{Lauraceae}

Ocotea indecora (Schott) Mez canela-sassafr

Persea americana Mill.

ás

abacateteiro $\mathrm{X}$

X SI

SI

\section{Lecythidaceae}

Lecythidaceae sp.

$\mathrm{X} \quad \mathrm{ST}$

\section{Leguminosae}

Bauhinia forficata Link.

Bauhinia sp. 1

Bauhinia sp. 2

Inga striata Benth.

Machaerium stipitatum Vogel

Piptadenia gonoacantha (Mart.)

J.F. Macbr.

Swartzia acutifolia Vogel

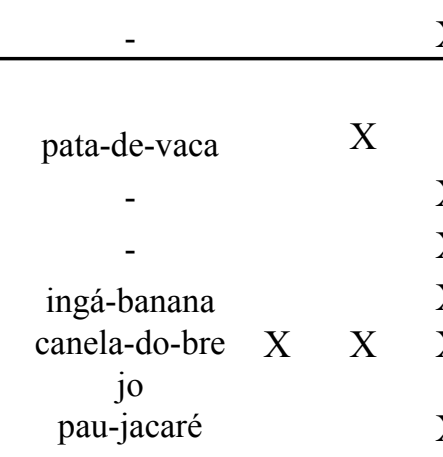

banha-de-gali nha

\section{Melastomataceae}

$\begin{array}{lllll}\text { Miconia cinnamomifolia (DC.) } & \text { jacatirão } & \text { X } & \text { PI } & \text { K.K.S.Costa } 16\end{array}$

Naudin

\section{Meliaceae}

Cedrela odorata L.

cedro-rosa

X ST

\section{Myrtaceae}

Myrcia splendens (Sw.) DC.

guamirim

$\begin{array}{ll}\mathrm{X} & \mathrm{SI}\end{array}$

Myrtaceae sp.

$\mathrm{X} \quad \mathrm{SC}$

\section{Nyctaginaceae}

Guapira opposita (Vell.) Reitz

maria-mole

$\mathrm{X}$

SI

\section{Primulaceae}

Myrsine coriacea (Sw.) R.Br. ex

Roem. \& Schult.

Myrsine umbellata Mart.

capororoca

X SI

K.K.S.Costa 14

capororoca-

X SI

K.K.S.Costa 05

\section{Rubiaceae}

Bathysa australis (A. St.-Hil.) K. quina-do-mat

Schum. 


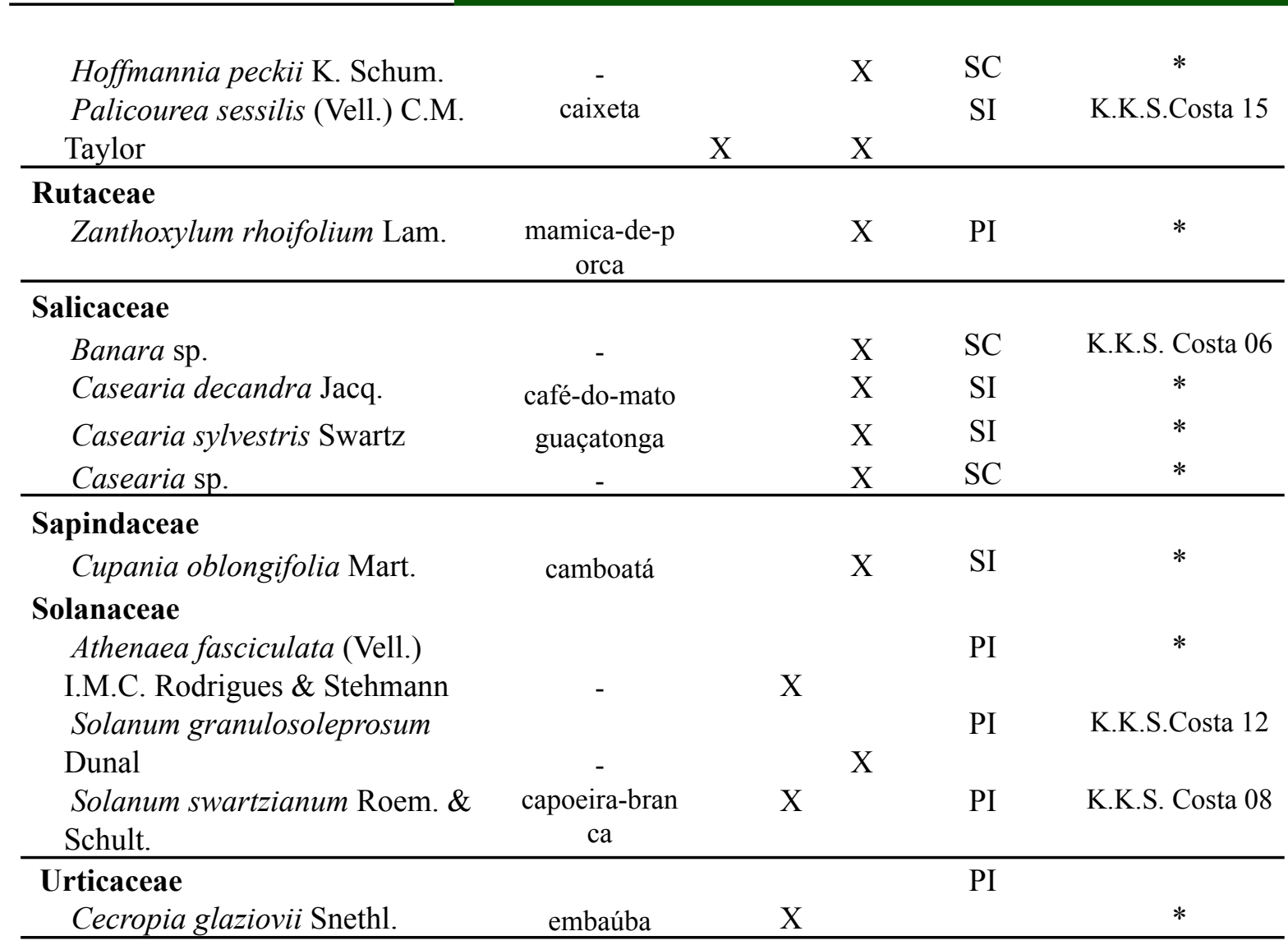

Fonte: Laboratório de Estudos Interdisciplinares Culturais e Ambientais UERJ/FFP.

Embora os ambientes de pousio avaliados ocupem uma área relativamente pequena, apresentam heterogeneidade florística, compartilhando poucas espécies (Figura 4), devido ao diferenciado tempo de regeneração da vegetação. Esse é um reflexo do processo de sucessão ecológica que acontece nesses fragmentos. As únicas espécies que ocorreram em mais de um sistema foram Vernonanthura polyanthes e Machaerirun stipitatum em PO I e PO II, além de Croton floribundus e Palicourea sessilis em PO I e FL (Tabela 2). Esse baixo número de espécies comuns está relacionado a pouca conectividade entre os três fragmentos que foram usados anteriormente para práticas agrícolas. Devido ao processo de sucessão ecológica, algumas espécies desaparecem e outras são agregadas ao sistema na medida em que ocorrem modificações estruturais na biocenose, alterando dessa forma a composição florística. A espécie que apresentou mais indivíduos em cada sistema foram Machaerium stipitatum em PO I e PO II, com 35 e 60\% respectivamente e Palicourea sessilis em FL, com 33\% dos indivíduos amostrados (Figura 5).

Figura 4: Diagrama de Venn contendo o número de espécies inventariadas nos sistemas de pousio em São Pedro da Serra, município de Nova Friburgo, estado do Rio de Janeiro, Brasil. 


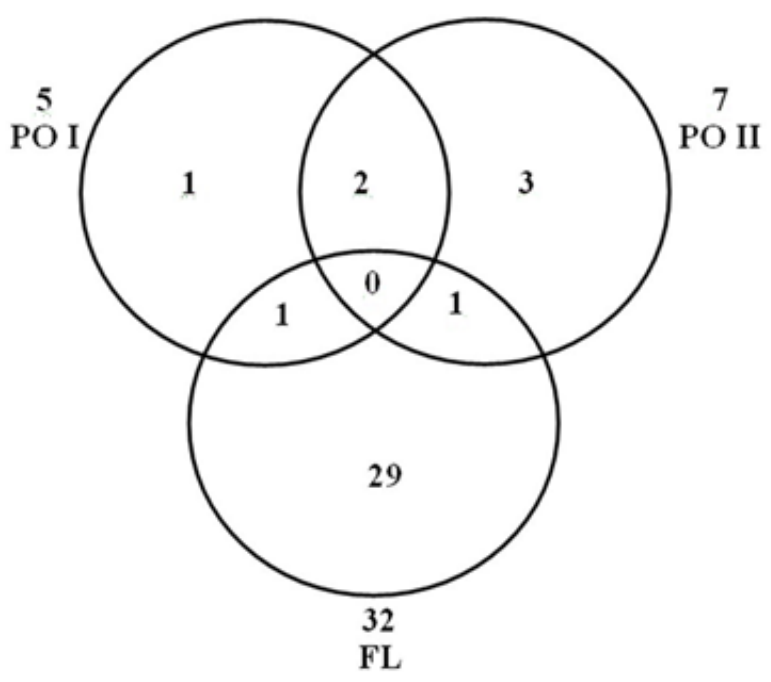

Fonte: Laboratório de Estudos Interdisciplinares Culturais e Ambientais UERJ/FFP.

Figura 5: Espécies com maior número de indivíduos nos sistemas de pousio em São Pedro da Serra, município de Nova Friburgo, estado do Rio de Janeiro, Brasil.

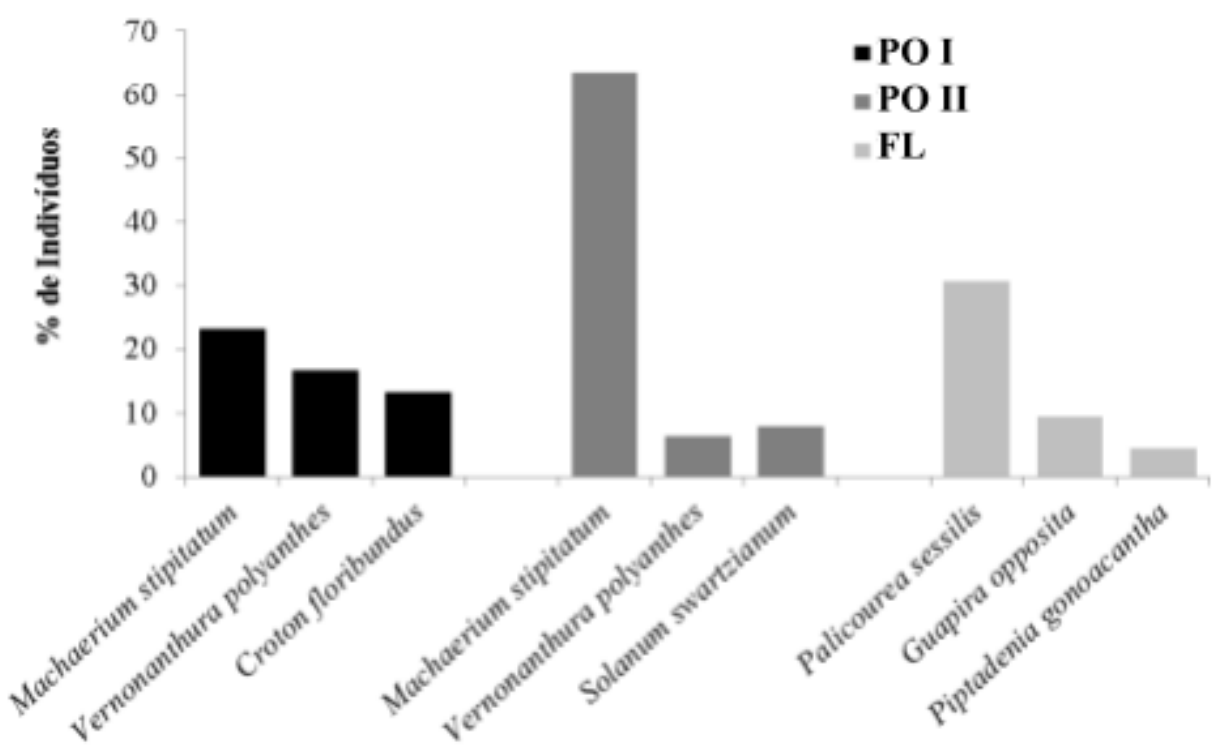

Fonte: Laboratório de Estudos Interdisciplinares Culturais e Ambientais UERJ/FFP.

A distribuição das espécies em cada sistema indica um gradiente sucessional na ordem PO I - PO II - FL. O sistema PO I apresenta três espécies pioneiras e uma secundária inicial (Palicourea sessilis). PO II aparece com cinco pioneiras e uma secundária inicial. Em FL predominam 13 espécies secundárias iniciais, seguidas de seis pioneiras e cinco secundárias tardias. Essa última categoria só aparece o sistema florestal com a presença de: Annona sylvatica, Ocotea indecora, Swartzia acutifolia, Cedrela odorata e Bathysa australis. O processo de sucessão ecológica está ocorrendo dentro do esperado, uma vez que em PO I e PO II predominam as pioneiras, espécies colonizadoras que conseguem se desenvolver em 
ambientes com pouca disponibilidade de nutrientes, como em áreas de pousio recém-abandonadas. Em FL observa-se a diminuição desse grupo ecológico e o aumento no número de espécies secundárias iniciais e tardias (Figura 6).

Figura 6: Número de espécies em relação ao estádio sucessional distribuídas nos sistemas de pousio em São Pedro da Serra, município de Nova Friburgo, estado do Rio de Janeiro, Brasil.

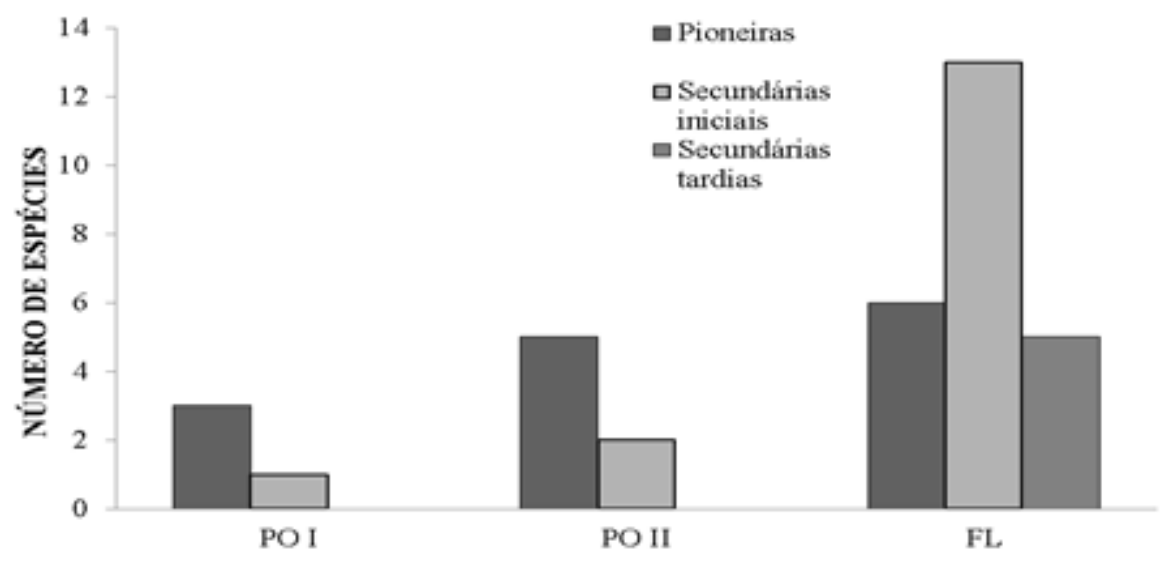

Fonte: Laboratório de Geociências da UERJ/FFP.

Em PO I foi observado um estrato arbóreo mais homogêneo, visto que a maioria das espécies é heliófila exigente de luminosidade. Em áreas recém-abandonadas as espécies pioneiras são fundamentais para iniciar o processo de sucessão primária. Machaerium stipitatum se destaca nesse sentido, por apresentar o maior número de indivíduos (7). No entanto, Vernonanthura polyanthes é a que demonstra maior adaptabilidade ao ambiente, apresentando as maiores alturas e diâmetros. Encontra-se estabelecida e em pleno processo de reprodução, sendo importante para a colonização inicial da área usada para agricultura e que passou ao estado de pousio. Em um estudo realizado em Bom Jardim, Nova Friburgo, essa espécie também foi encontrada com abundância em fragmentos florestais com idade até cinco anos anteriormente submetidos ao pousio (MAGALHÃES; FREITAS, 2003).

Em PO II o percentual de pioneiras é um pouco maior (83,3\%). As espécies encontradas nesse grupo ecológico foram Machaerium stipitatum, Solanum swartzianum, Athenaea fasciculata, Vernonanthura polyanthes e Cecropia glaziovii (Tabela 2). As únicas secundárias iniciais encontradas foram Bauhinia forficata e Piptadenia gonoacantha, com ocorrências associadas a rebrota, característica muito comum em áreas de pousio. Possivelmente resquício da vegetação pretérita ao desmatamento e queima para plantio de espécies de interesse agrícola. Machaerium stipitatum foi a que apresentou maior abundância de indivíduos nesse sistema (60\%), sendo observada plenamente estabelecida e em processo de reprodução. É favorecida pelo seu processo de dispersão anemocórica de sementes, que são produzidas em grande quantidade. Segundo Penha (1998), apresenta alta capacidade de rebrota a partir de raízes gemíferas, que representa um relevante mecanismo de colonização em locais onde há baixa disponibilidade de nutrientes, como observado em áreas de pousio recém-abandonadas. A possibilidade das plantas investirem mais em reprodução vegetativa é 
considerada uma importante estratégia de autorregulação populacional, diminuindo a variância anual de recrutamento e o tempo necessário para a população atingir uma distribuição estável de idades. Assim a rebrota passa a minimizar os efeitos da perturbação causada pela supressão da vegetação. As espécies que apresentam essas características são menos afetadas pelos efeitos de perda de polinizadores, dispersores, dificuldades de germinação e recrutamento (BOND; MIDGLEY, 2001).

Apesar da literatura indicar o estágio sucessional de Machaerium stipitatum como secundária inicial, no presente estudo essa espécie foi categorizada como pioneira, visto se mostrar tolerante a luminosidade em todo o seu ciclo de vida, além de assumir comportamento de espécie colonizadora. Alguns estudos apontam que em áreas degradadas onde há a presença dessa espécie ocorre melhoria das condições nutricionais do solo, por tratar-se de uma leguminosa fixadora de nitrogênio. Esse elemento mineral passa a ser então disponibilizado para as demais espécies que sem estabelecem nesses ambientes (SILVA, 2005; LIMA, 2006; LIMA et al., 2006). Sua eficácia para a melhoria da qualidade nutricional do solo foi demonstrada em pesquisas realizadas na área de estudo, na qual PO II foi o sistema que apresentou as maiores taxas de nitrogênio no solo (LIMA et al., 2006). O mesmo foi observado por Silva (2005) em solos com altas taxas de nitrogênio relacionados às áreas de PO I, PO II e FL. Há tanto uma concentração elevada na profundidade mais superficial (0-5 $\mathrm{cm})$, quanto na camada de subsuperfície $(10-15 \mathrm{~cm})$.

Em FL há predominância de espécies secundárias iniciais (Tabela 2), o aparecimento de secundárias tardias e a diminuição no número de espécies pioneiras, evidenciam o avanço no processo de sucessão secundária. Palicourea sessilis aparece com o maior número de indivíduos (42), seguida de Guapira opposita (13), Piptadenia gonoacantha e Croton floribundus (6, cada). Dentre as pioneiras, destaca-se Miconia cinnamomifolia (jacatirão), que é categorizada em estádio inicial e ter apresentado somente cinco indivíduos no sistema. Tem sua ocorrência associada a capoeirões e florestas secundárias de encostas. É uma espécie longeva, podendo sobreviver por quase de 100 anos, sendo observada muitas vezes dominando capoeiras de 30 a 40 anos. Normalmente é associada a ambientes onde ocorreram antigas roças caiçaras, sendo considerada indicadora desse tipo de ambiente em uma floresta, além de ser chave no processo de regeneração natural da vegetação (OLIVEIRA, 2002; OLIVEIRA, 2007; OLIVEIRA et al., 2008).

A ocorrência de cinco espécies secundárias tardias demonstra o avanço sucessional no sistema. A presença de secundárias iniciais e pioneiras já bem desenvolvidas, com as maiores alturas e diâmetros, oferece o sombreamento necessário para o desenvolvimento de espécies intolerantes a luminosidade, como as desse grupo ecológico. Por outro lado, as secundárias tardias apareceram com médias de altura e diâmetro inferiores, indicando que são indivíduos jovens. Segundo Roderjan e Kuniyoshi (1988), é no ambiente da floresta secundária que começam a surgir as espécies características da floresta madura, assim como epífitas e trepadeiras, praticamente inexistentes nos estágios anteriores. Percebem-se algumas dessas características no fragmento florestal estudado, como a presença de trepadeiras lenhosas 
chegando às copas das árvores e algumas epífitas. É um indicio importante do processo de sucessão mais avançado, uma vez que nos fragmentos mais jovens PO I e PO II essas formas de vida estavam ausentes e somente trepadeiras herbáceas foram observadas.

De acordo como que foi apresentado estima-se que nenhum dos fragmentos analisados chegou à estabilidade sucessional. PO I e PO II possuem pequena riqueza de espécies, baixas médias de altura e diâmetro, existência de um estrato único com presença espécies preponderantemente exigentes de luz, ausência de epífitas e presença de trepadeiras herbáceas. Dessa forma, considera-se que esses fragmentos estejam em estágio inicial de regeneração. Em trabalho realizado em uma Floresta Ombrófila Densa no Paraná, Roderjan e Kuniyoshi (1988) observaram essas características em um fragmento em regeneração, ao qual determinaram estar em fase de capoeira. Esses ambientes mostram um estágio de acentuada uniformidade fitofisionômica, com reduzido número de espécies.

No fragmento florestal ocorre um avanço sucessional, se comparado a PO I e PO II. A riqueza de espécies aumenta e observam-se indivíduos com até 15 metros de altura e médias diamétricas superiores. A presença de espécies secundárias iniciais jovens e pioneiras de grande porte como Piptadenia gonoachanta e Miconia cinnamomifolia, indica que o ambiente difere dos primeiros sistemas, criando o sombreamento necessário ao estabelecimento das espécies de sub-bosque. O predomínio de indivíduos de Palicourea sessilis (35\%) mostra que a comunidade encontra-se instável, uma vez que as condições favorecem sua reprodução e estabelecimento na comunidade em detrimento de outras espécies. Essa fase seria denominada capoeirão por Roderjan e Kuniyoshi (1988), pois o dossel é mais diversificado, chegando ao final de seu desenvolvimento com a presença de dois estratos arbóreos, porém, com uma separação não muito bem definida. Se o processo de regeneração nesse sistema transcorrer com o mínimo de perturbações, o fragmento tende a atingir o porte de uma floresta secundária, a qual ostenta uma vegetação mais heterogênea, com dois estratos arbóreos definidos e um terceiro em formação.

A regeneração em comunidades vegetais após serem queimadas em sistemas slash-and-burn é variável e está relacionada com a resposta das espécies individuais, que por sua vez são influenciadas pelas características ambientais e perturbações posteriores. $\mathrm{O}$ crescimento da vegetação se dará em relação à interação de uma série de fatores como o regime do fogo (intensidade e severidade), as características do local (topografia, clima e solo) e as características intrínsecas de cada planta (espécie, vigor vegetativo e idade). Outros atributos como a perturbação (seca, alterações no solo, pragas, entre outras) também podem interferir na recuperação das plantas (CATRY et al., 2010), alterando o processo natural da regeneração da vegetação.

Os sistemas de pousio foram avaliados em relação aos índices de diversidade de Shannon-Weaver (H') e de Simpson (D) e os resultados constam da tabela 3. Nessa análise foram incluídas as espécies indeterminadas também. Os valores obtidos foram baixos, condizentes com o grau de perturbação antrópica e idades diferentes de regeneração dos 
sistemas: PO I (1,635 nat.ind. $\left.{ }^{-1}\right)$, PO II (1,227 nat.ind. $\left.{ }^{-1}\right)$ e FL (2,626 nat.ind. $\left.{ }^{-1}\right)$. O índice de Shannon-Weaver relaciona a riqueza e a abundância de espécies, considerando a proporção com que os indivíduos de cada espécie aparecem na área amostrada. Embora haja algumas restrições ao uso desse índice, este permite comparar diferentes áreas amostradas em lugares distintos por suas condições ambientais intrínsecas. Na Mata Atlântica os valores variam entre 1,5 a 3,5 nat.ind. ${ }^{-1}$ (MARTINS, 1991), sendo raros aqueles acima disso, como verificado em Pariquera-Açu (SP) (4,06 nat.ind..$^{-1}$ ) (SZTUTMAN; RODRIGUES, 2002). Esse é um remanescente florestal estudado no Brasil que apresenta uma diversidade considerável, visto ser uma floresta bem conservada e mais madura.

Esperavam-se valores com aumento gradual do menor para o maior sistema de acordo com o tempo de regeneração da vegetação. No entanto, o índice obtido em PO II foi menor do que em PO I, que representa o sistema mais jovem (4 a 7 anos). Esse resultado está relacionado à predominância da presença de Machaerium stipitatum nesse sistema (60\%), que contribuiu para a diminuição do valor obtido, espelhando a baixa diversidade encontrada em PO II. Por outro lado, o índice de Simpson (D) foi inversamente proporcional ao índice de Shannon-Weaver em todos os sistemas, uma vez que quanto menor a diversidade, maior esse valor (Figura 7).

Tabela 3: Índice de diversidade de Shannon-Weaver (H') e índice de Simpson (D) em sistemas de pousio em São Pedro da Serra, município de Nova Friburgo, estado do Rio de Janeiro, Brasil. $\mathrm{N}=$ número de indivíduos e $\mathrm{S}=$ número de espécies.

\begin{tabular}{|c|c|c|c|c|}
\hline Sistema & $\mathbf{N}$ & $\mathbf{S}$ & $\mathbf{H}^{\prime}$ (nat.ind. $^{-1}$ ) & D \\
\hline PO I & 20 & 7 & 1,635 & 0,195 \\
\hline PO II & 58 & 6 & 1,227 & 0,401 \\
\hline $\mathrm{FL}$ & 118 & 32 & 2,626 & 0,147 \\
\hline
\end{tabular}

Fonte: Laboratório de Geociências da UERJ/FFP.

Figura 7: Variação dos índices de diversidade Shannon-Weaver (H') (nat.ind.-1) e Simpson (D) em sistemas de pousio em São Pedro da Serra, município de Nova Friburgo, estado do Rio de Janeiro, Brasil.

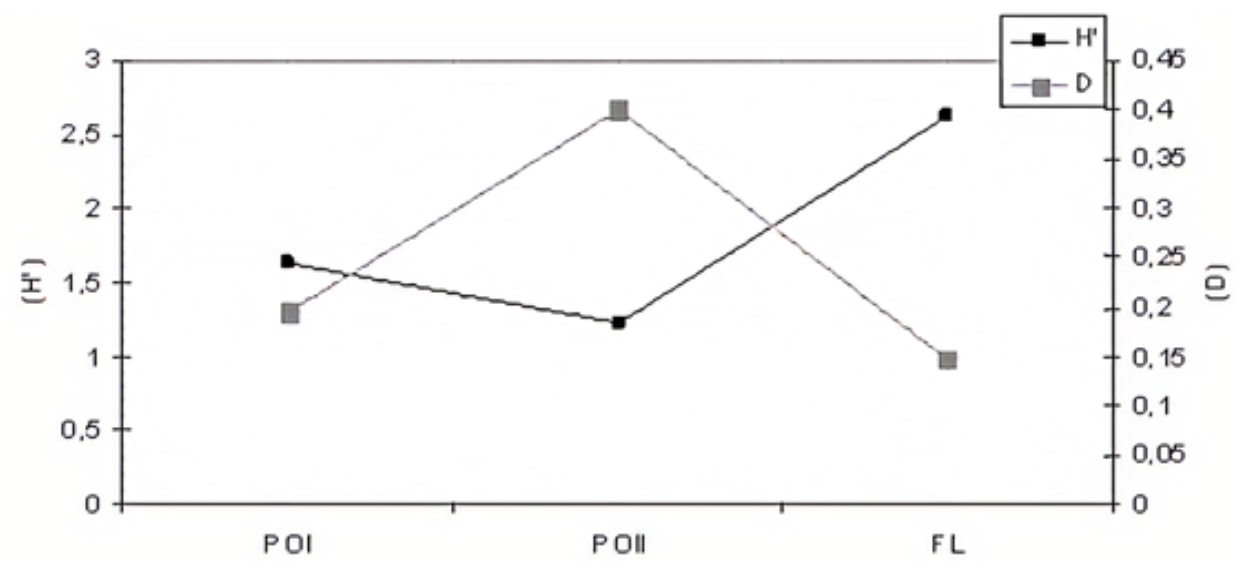


Fonte: Laboratório de Geociências da UERJ/FFP.

As dificuldades para confrontar estudos florísticos são várias, dentre elas, ressaltam-se as diferenças metodológicas, tamanho da área amostral, critério de inclusão do DAP, topografia e tipologia do solo da área de estudo. Porém, apesar do índice de diversidade de espécies ser influenciado pelo desenho amostral utilizado, buscou-se comparar os resultados obtidos nos sistemas de pousio em São Pedro da Serra com outros inventários feitos em áreas antes utilizadas para agricultura e com a mesma fisionomia. O índice de Shannon-Weaver encontrado em FL foi inferior a todos os valores encontrados na floresta tropical montana nesses trabalhos (PESSOA; GUEDES BRUNI; KURTZ, 1997; TABARELLI; MANTOVANI, 1997; MAGALHÃES; FREITAS, 2004; OLIVEIRA et al., 2008; SILVA, 2009). O valor mais alto foi observado por Pessoa, Guedes Bruni e Kurtz. (1997) em Macaé de Cima, Nova Friburgo (RJ), seguido por Tabarelli e Mantovani (1997) em São Paulo, Silva (2009), Magalhães e Freitas (2004) em Nova Friburgo (RJ) e Oliveira et al. (2008) na Ilha Grande $(\mathrm{RJ})$.

Mesmo considerando as diferenças no tamanho da área amostral é possível confrontar o sistema florestal de pousio em São Pedro da Serra com outras áreas. FL (2,62 nat.ind..$^{-1}$.) ficou mais próxima dos menores valores obtidos na Ilha Grande (2,68 nat.ind. $\left.{ }^{-1}\right)$ (OLIVEIRA et al., 2008) e em Bom Jardim (2,81 nat.ind..$\left.^{-1}\right)$ (MAGALHÃES; FREITAS, 2004). Na Ilha Grande a área estudada tem o tempo de regeneração de 10 anos, inferior ao sistema FL (50 a 70 anos). Mas é necessário considerar o bom estado de conservação da matriz florestal, onde o fragmento insular se insere, além dos altos índices de umidade locais (OLIVEIRA et al., 2008). Nesse caso, a regeneração da vegetação avançou mais rapidamente do que em São Pedro da Serra. Fez diferença grande parte dessa ilha estar incluída em UC de proteção integral.

Em Bom Jardim, a amostragem foi feita em uma pequena propriedade rural com histórico de atividades agrícolas semelhantes aquelas praticadas em São Pedro da Serra, com a mesma metodologia e critérios de inclusão (MAGALHÃES; FREITAS, 2004). Trata-se de um fragmento com tamanho reduzido, o que implica na diminuição das populações das espécies arbóreas, alteração nos padrões de migração e dispersão de propágulos, com ambientes expostos a condições externas adversas anteriores a perturbação antrópica. Isso resultou na deterioração da diversidade biológica ao longo do tempo. Além disso, quanto menor é o fragmento, maior é a exposição aos efeitos de borda (CHAZDON, 2016). Apesar de FL apresentar baixo índice de diversidade, o número de espécies encontradas entre essas áreas foi muito próximo, indicando que a velocidade de regeneração do sistema florestal em São Pedro da Serra é compatível com demais ambientes que passaram por pousio e que tenham histórico de fragmentação semelhante. Além de ser ambientes próximos, o que tem influência também em relação ao compartilhamento de espécies, já que as matrizes fornecedoras de propágulos são semelhantes. 
Os resultados da análise estrutural mostram um aumento em todos os parâmetros analisados, com exceção da mortalidade e troncos múltiplos (Tabela 4). Em PO I foi encontrada uma mortalidade de $33,33 \%$ do total de indivíduos, devido ao estágio sucessional em que se encontra. Em sua maioria, as espécies pioneiras possuem ciclo de vida curto, principalmente Vernonanthura polyanthes, presente neste sistema. Outra questão a ser levada em consideração é o efeito de borda, que influencia nesse processo, possibilitando o aumento na incidência de perturbações como, por exemplo, os ventos, o que acaba afetando negativamente a comunidade.

O sistema FL apresentou mortalidade superior a PO II (13,97\%), o que possivelmente é resultado do avanço do processo sucessional, além do efeito de borda. Nesse sistema, o dossel é mais conspícuo causando o sombreamento florestal. Isso acaba provocando o aumento da taxa de mortalidade de espécies pioneiras, que são dependentes de luminosidade.

Tabela 4: Parâmetros fitossociológicos gerais da estrutura da vegetação em sistemas de pousio em São Pedro da Serra, município de Nova Friburgo, estado do Rio de Janeiro, Brasil.

\begin{tabular}{lccc}
\hline & PO I & PO II & FL \\
\hline Área amostrada $\left(\mathrm{m}^{2}\right)$ & 600 & 600 & 600 \\
Número de indivíduos & 30 & 63 & 136 \\
Densidade (ind./ha) & 1333.33 & 3866.67 & 7866,7 \\
Área basal (m $\left.{ }^{2}\right)$ & 0.088 & 0.443 & 1.566 \\
Diâmetro máximo (cm) & 19.36 & 33.99 & 48.33 \\
Diâmetro mínimo (cm) & 4.77 & 4.77 & 4.77 \\
Diâmetro médio (cm) & 5,41 & 6,68 & 10.46 \\
Altura máxima (m) & 7.00 & 12.50 & 15.00 \\
Altura mínima (m) & 2.50 & 1.00 & 1.00 \\
Altura média (m) & 4.27 & 4.55 & 6.02 \\
Troncos múltiplos (\%) & 6.67 & 19,0 & 13,98 \\
Árvores mortas (\%) & 33.33 & 7.94 & 13,97 \\
\hline
\end{tabular}

Fonte: Laboratório de Geociências da UERJ/FFP.

Com relação aos troncos múltiplos, o sistema PO II apresentou o maior valor $(19,0 \%)$ dos troncos perfilhados, seguido por FL (13,98\%) e PO I (6.67\%). Este é um aspecto importante observado em áreas submetidas ao pousio. Na limpeza do terreno para o plantio algumas árvores são cortadas, mas mantidas vivas, com o objetivo de facilitar a recolonização do terreno quando for novamente abandonado. Mesmo passando por queima, os tocos das espécies mais generalistas podem rebrotar.

Os índices de densidade total, área basal, diâmetro e altura máxima e mínima seguiram o gradiente temporal esperado. De acordo com o gráfico abaixo (Figura 8), a distribuição diamétrica segue a ordem $\mathrm{POI}<\mathrm{POII}<$ FL. Em PO I um indivíduo de Croton floribundus apresentou o maior diâmetro (19,4 cm). Em PO II destacou-se Cecropia glaziovii $(34,0 \mathrm{~cm}) \mathrm{e}$ em FL uma espécie indeterminada $(48,3 \mathrm{~cm})$ e na segunda posição Piptadennia gonoachanta $(42,3 \mathrm{~cm})$. As espécies que apresentaram as maiores médias diamétricas foram: Persea 
americana (abacateiro) em PO I (11,0 cm), Bauhinia forficata (pata-de-vaca) em PO II (19,5 $\mathrm{cm})$ e em FL uma espécie indeterminada $(48,3 \mathrm{~cm})$.

Figura 8: Distribuição diamétrica nos indivíduos amostrados nos sistemas de pousio em São Pedro da Serra, município de Nova Friburgo, estado do Rio de Janeiro, Brasil.

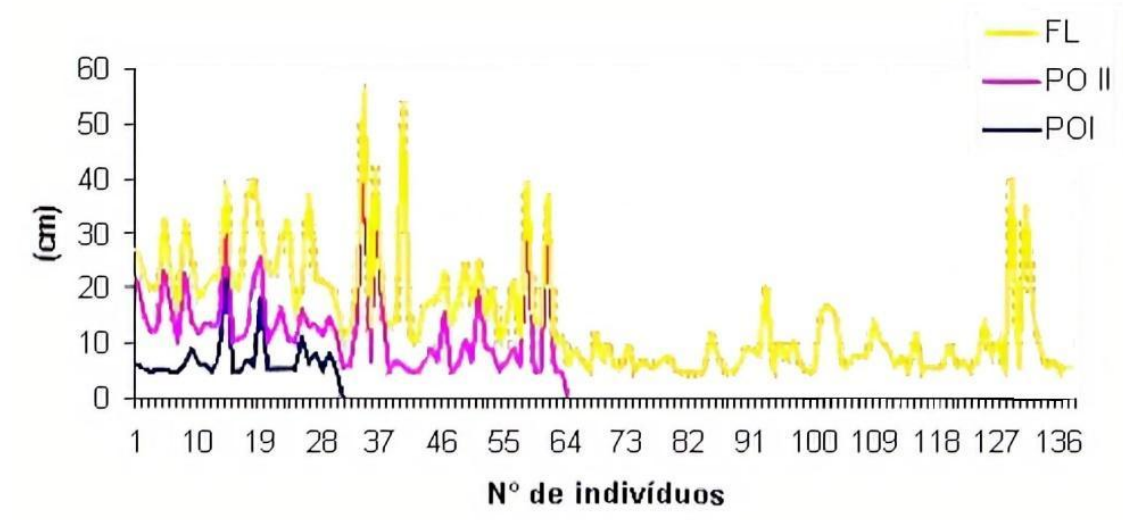

Fonte: Laboratório de Geociências da UERJ/FFP.

Em PO I um indivíduo de Croton floribundus apresentou o maior diâmetro (19,4 cm). Em PO II destacou-se Cecropia glaziovii $(34,0 \mathrm{~cm})$ e em FL uma espécie indeterminada (48,3 $\mathrm{cm})$ e na segunda posição Piptadenia gonoachanta $(42,3 \mathrm{~cm})$. As espécies que apresentaram as maiores médias diamétricas foram: Persea americana (abacateiro) em PO I $(11,0 \mathrm{~cm})$, Bauhinia forficata (pata-de-vaca) em PO II $(19,5 \mathrm{~cm})$ e em FL uma espécie indeterminada $(48,3 \mathrm{~cm})$.

A distribuição de altura também seguiu um padrão ascendente. $\mathrm{O}$ indivíduo mais alto em PO I foi um Croton floribundus (7,0 m), em PO II Cecropia glaziovii (10,0 m) e em FL Miconia cinnamomifolia $(15,0 \mathrm{~m})$. A maioria dos indivíduos dos três sistemas se concentrou na segunda classe, com diâmetros entre 3,1 e 5,0 m (Figura 9). Em PO I, 16,66\% dos indivíduos estão na primeira classe com até $3,0 \mathrm{~m}$ e a maioria $(63,33 \%)$ se encontra na segunda. Em PO II, a segunda classe também agrega a maior parte dos indivíduos amostrados $(69,9 \%)$, demonstrando a maior homogeneidade na fisionomia do fragmento. Em FL, apesar da segunda classe, que vai até 5,0 m, agregar também a maioria dos indivíduos (35,5\%), ocorre uma distribuição mais equilibrada entre as alturas. A classe três e quatro apresentou um número considerável de indivíduos, respectivamente com 21,5 e 11,1\%. Avaliando essas informações em FL percebe-se que há maior estratificação arbórea no sistema, devido à presença de espécies em diferentes estádios sucessionais, apresentando diferentes necessidades, principalmente com relação à luminosidade. As espécies exigentes de luz tendem a alcançar o dossel florestal, as secundárias iniciais nascem na sombra e buscam a luminosidade em seu desenvolvimento e as secundárias tardias, intolerantes à luz, se desenvolvem no sub-bosque. Essas características contribuem para o desenvolvimento de uma paisagem florestal mais heterogênea, pelo menos em nível estrutural. 
Figura 9: Distribuição dos indivíduos amostrados por classes de altura nos sistemas de pousio em São Pedro da Serra, município de Nova Friburgo, estado do Rio de Janeiro, Brasil.

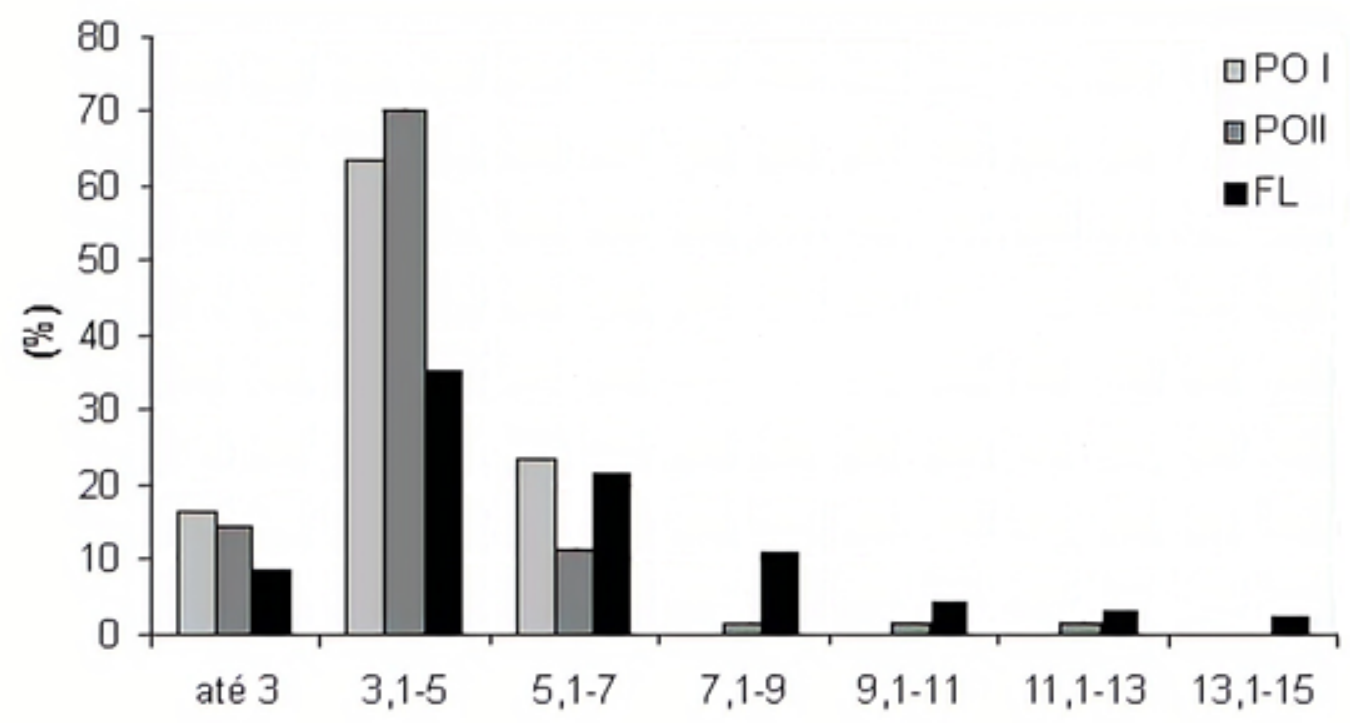

Fonte: Laboratório de Geociências da UERJ/FFP.

Os parâmetros fitossociológicos são apresentados na tabela 5 em ordem decrescente de valor de importância (IVI). No sistema PO I os maiores valores obtidos foram de Croton floribundus (84,74\%), Machaerium stipitatum (71,44\%), Vernonanthura polyanthes $(63,33 \%)$ e Persea americana (25,71\%). No sistema PO II Machaerium stipitatum (116,0\%), Athenaea fasciculata (57,90\%), Bauhinia forficata (37,37\%) e Cecropia glaziovii (35,50\%). Em FL Palicourea sessilis (54,69\%), Piptadenia gonoacantha (32,80\%), Guapira opposita (24,10\%) e Croton floribundus (18,94\%). Este índice reflete a importância da espécie na biocenose florestal somando-se os valores de densidade, dominância e frequência. Quanto mais alto é o valor de uma espécie em relação às demais, menor é a diversidade do fragmento. E nesse sentido, os resultados apontam mais uma vez para a menor diversidade do sistema PO II.

Tabela 5: Descritores fitossociológicos das espécies em ordem decrescente de valores de importância amostradas com critério de inclusão DAP $\geq 5,0 \mathrm{~cm}$ em sistemas de pousio em São

Pedro da Serra, município de Nova Friburgo, estado do Rio de Janeiro, Brasil. $\mathrm{N}-\mathrm{n}^{\mathrm{o}}$ de indivíduos; DA - densidade absoluta; DR - densidade relativa; FA - frequência absoluta; FR - Frequência Relativa; DoA - dominância absoluta; DoR - dominância relativa; IVI - índice de valor de importância.

\begin{tabular}{l|c|c|c|c|c|c|c|c}
\hline \multicolumn{1}{c|}{ ESPÉCIE } & $\mathbf{N}$ & $\begin{array}{c}\text { DA } \\
\text { (ind./ha) }\end{array}$ & $\begin{array}{c}\text { DR } \\
(\%)\end{array}$ & $\begin{array}{c}\text { FA } \\
(\%)\end{array}$ & $\begin{array}{c}\text { FR } \\
(\%)\end{array}$ & $\begin{array}{c}\text { DoA } \\
\left(\mathrm{m}^{2}\right)\end{array}$ & $\begin{array}{c}\text { DoR } \\
(\%)\end{array}$ & $\begin{array}{c}\text { IVI } \\
(\%)\end{array}$ \\
\hline \multicolumn{1}{c}{ PO I } \\
\hline Croton floribundus \\
Machaerium stipitatum & 4 & 266,7 & 20,00 & 66,67 & 20,00 & 0,0099 & 44,74 & 84,74 \\
Vernonanthura polyanthes & 5 & 466,7 & 35,00 & 66,67 & 20,00 & 0,0021 & 16,44 & 71,44 \\
Persea americana & 5 & 333,3 & 25,00 & 66,67 & 20,00 & 0,0032 & 18,33 & 63,33 \\
Indeterminada 1 & 1 & 66,7 & 5,00 & 33,33 & 10,00 & 0,0095 & 10,71 & 25,71 \\
& 1 & 66,7 & 5,00 & 33,33 & 10,00 & 0,0032 & 3,60 & 18,60
\end{tabular}




\begin{tabular}{|c|c|c|c|c|c|c|c|c|}
\hline Palicourea sessilis & 1 & 66,7 & 5,00 & 33,33 & 10,00 & 0,0030 & 3,42 & 18,42 \\
\hline Indeterminada 2 & 1 & 66,7 & 5,00 & 33,33 & 10,00 & 0,0024 & 2,76 & 17,76 \\
\hline \multicolumn{9}{|l|}{ PO II } \\
\hline Machaerium stipitatum & 35 & 2333,3 & 60,34 & 66,67 & 22,22 & 0,0043 & 34,28 & 116,85 \\
\hline Athenaea fasciculata & 11 & 733,3 & 18,97 & 66,67 & 22,22 & 0,0067 & 16,71 & 57,90 \\
\hline Bauhinia forficata & 3 & 200,0 & 5,17 & 33,33 & 11,11 & 0,0311 & 21,09 & 37,37 \\
\hline Cecropia glaziovii & 2 & 133,3 & 3,45 & 33,33 & 11,11 & 0,0464 & 20,94 & 35,50 \\
\hline Solanum swartzianum & 5 & 266,7 & 6,90 & 66,67 & 22,22 & 0,0058 & 5,25 & 34,37 \\
\hline Vernonanthura polyanthes & 3 & 200,0 & 5,17 & 33,33 & 11,11 & 0,0025 & 1,72 & 18,00 \\
\hline \multicolumn{9}{|l|}{ FL } \\
\hline Palicourea sessilis & 42 & 2800,0 & 35,59 & 100,00 & 6,12 & 0,0048 & 12,97 & 54,69 \\
\hline Piptadenia gonoacantha & 6 & 400,0 & 5,08 & 100,00 & 6,12 & 0,0564 & 21,59 & 32,80 \\
\hline Guapira opposita & 13 & 866,7 & 11,02 & 100,00 & 6,12 & 0,0084 & 6,96 & 24,10 \\
\hline Croton floribundus & 6 & 400,0 & 5,08 & 33,33 & 6,12 & 0,0202 & 7,74 & 18,94 \\
\hline Indeterminada 3 & 1 & 66,7 & 0,85 & 100,00 & 2,04 & 0,1835 & 11,72 & 14,60 \\
\hline Miconia cinnamomifolia & 5 & 333,3 & 4,24 & 100,00 & 6,12 & 0,0119 & 3,81 & 14,17 \\
\hline Lacistema pubescens & 5 & 333,3 & 4,24 & 33,33 & 6,12 & 0,0065 & 2,07 & 12,42 \\
\hline Lecythidaceae sp. 1 & 1 & 66,7 & 0,85 & 66,67 & 2,04 & 0,1264 & 8,07 & 10,96 \\
\hline Casearia sylvestris & 3 & 200,0 & 2,54 & 66,67 & 4,08 & 0,0203 & 3,88 & 10,51 \\
\hline Casearia decandra & 5 & 333,3 & 4,24 & 66,67 & 4,08 & 0,0046 & 1,46 & 9,78 \\
\hline Myrsine coriacea & 4 & 266,7 & 3,39 & 33,33 & 4,08 & 0,0066 & 1,69 & 9,17 \\
\hline Apocynaceae sp. 1 & 2 & 133,3 & 1,69 & 66,67 & 2,04 & 0,0300 & 3,84 & 7,57 \\
\hline Annona sylvatica & 2 & 133,3 & 1,69 & 66,67 & 4,08 & 0,0078 & 0,99 & 6,77 \\
\hline Myrcia splendens & 2 & 133,3 & 1,69 & 33,33 & 4,08 & 0,0020 & 0,26 & 6,04 \\
\hline Banara sp. & 1 & 66,7 & 0,85 & 33,33 & 2,04 & 0,0340 & 2,17 & 5,06 \\
\hline Bauhinia sp.1 & 2 & 133,3 & 1,69 & 33,33 & 2,04 & 0,0077 & 0,98 & 4,72 \\
\hline Myrtaceae sp. 1 & 1 & 66,7 & 0,85 & 33,33 & 2,04 & 0,0276 & 1,76 & 4,65 \\
\hline Piptocarpha macropoda & 1 & 66,7 & 0,85 & 33,33 & 2,04 & 0,0263 & 1,68 & 4,57 \\
\hline Casearia sp. & 1 & 66,7 & 0,85 & 33,33 & 2,04 & 0,0224 & 1,43 & 4,32 \\
\hline Myrsine umbellata & 1 & 66,7 & 0,85 & 33,33 & 2,04 & 0,0195 & 1,25 & 4,13 \\
\hline Inga striata & 2 & 133,3 & 1,69 & 33,33 & 2,04 & 0,0031 & 0,39 & 4,13 \\
\hline Cupania oblongifolia & 2 & 133,3 & 1,69 & 33,33 & 2,04 & 0,0025 & 0,32 & 4,06 \\
\hline Cedrela odorata & 1 & 66,7 & 0,85 & 33,33 & 2,04 & 0,0082 & 0,52 & 3,41 \\
\hline Ocotea indecora & 1 & 66,7 & 0,85 & 33,33 & 2,04 & 0,0067 & 0,43 & 3,32 \\
\hline Solanum granulosoleprosum & 1 & 66,7 & 0,85 & 33,33 & 2,04 & 0,0060 & 0,38 & 3,27 \\
\hline Hoffmannia dusenii & 1 & 66,7 & 0,85 & 33,33 & 2,04 & 0,0053 & 0,34 & 3,23 \\
\hline Xylopia brasiliensis & 1 & 66,7 & 0,85 & 33,33 & 2,04 & 0,0046 & 0,29 & 3,18 \\
\hline Bauhinia sp. 2 & 1 & 66,7 & 0,85 & 33,33 & 2,04 & 0,0046 & 0,29 & 3,18 \\
\hline Swartzia acutifolia & 1 & 66,7 & 0,85 & 33,33 & 2,04 & 0,0035 & 0,22 & 3,11 \\
\hline Sparattosperma leucanthum & 1 & 66,7 & 0,85 & 33,33 & 2,04 & 0,0032 & 0,20 & 3,09 \\
\hline Zanthoxylum rhoifolium & 1 & 66,7 & 0,85 & 33,33 & 2,04 & 0,0023 & 0,15 & 3,04 \\
\hline Bathysa australis & 1 & 66,7 & 0,85 & 33,33 & 2,04 & 0,0020 & 0,13 & 3,02 \\
\hline
\end{tabular}

Fonte: Laboratório de Estudos Interdisciplinares Culturais e Ambientais UERJ/FFP.

\section{CONSIDERAÇÕES FINAIS}

Os resultados mostram que os sistemas de pousio em São Pedro da Serra são compatíveis com os parâmetros apresentados na resolução do CONAMA $\mathrm{n}^{\circ} 6$, de 4 de maio de 1994, que especifica a caracterização sucessional da vegetação no estado do Rio de Janeiro (CONAMA, 1994). De acordo com essa resolução, os fragmentos PO I e PO II encontram-se 
no estágio inicial de regeneração e, desta forma, seria possível a continuidade da prática de pousio realizada pelos agricultores locais. A vegetação pode ser suprimida para novos plantios atendendo o que dispõe o artigo 25 da Lei Federal $n^{\circ} 11.428 / 06$, de 22 de dezembro de 2006, a Lei da Mata Atlântica (BRASIL, 2006). Em FL essa permissão é mais restritiva, uma vez que esse fragmento florestal secundário encontra-se em estágio médio de regeneração. A autorização do corte da vegetação para uso agrícola por comunidades tradicionais e pequenos produtores em sistema de pousio só é possível quando a presença de espécies pioneiras é superior a $60 \%$ em relação às demais espécies, o que não é o caso desse sistema. Além disso, o inciso III dessa lei não permite a supressão da vegetação em áreas de preservação permanente como, por exemplo, topos de morros, mesmo para práticas agrícolas tradicionais.

O Decreto Lei Federal $n^{0}$ 6.660, de 21 de novembro de 2008, que regulamenta a Lei Federal $n^{0} 11.428$, dispõe sobre a utilização e proteção da vegetação nativa da Mata Atlântica. Em seu capítulo VI trata das áreas de pousio, considerando que essa prática implica na interrupção de atividades agrícolas, pecuárias ou silviculturais por até dez anos, para possibilitar a recuperação de fertilidade do solo. Somente autoriza a supressão da vegetação com a anuência do órgão ambiental competente em áreas onde é comprovado o uso tradicional da terra em até dois hectares por ano. O corte da vegetação secundária em estágio médio de regeneração em pequenas propriedades é tratado no capítulo IX e implica numa série de exigências legais que visam regularizar e compatibilizar a atividade agrícola em pequenas comunidades e a conservação ambiental (BRASIL, 2008).

No entanto, em São Pedro da Serra os agricultores estão alterando as práticas desse sistema agrícola tradicional, comprometendo sua sustentabilidade. Isso ocorre para que os agricultores não sejam punidos legalmente pelos danos ambientais ocasionados ao desmatar a vegetação secundária na Mata Atlântica para plantio. Contudo, a diminuição do período destinado ao pousio após o slash-and-burn encurta o tempo de regeneração natural da vegetação, afetando os serviços ecossistêmicos providos pelas florestas. A intensificação agrícola altera a resiliência desse tipo de sistema, aumentando a pressão sobre as áreas florestadas. Daí a necessidade de produzir conhecimento baseado na ciência para que se estabeleçam estratégias que permitam o uso da terra em consonância com a conservação ambiental. É fundamental o diálogo com o órgão gestor da APA de Macaé de Cima, agricultores e pesquisadores para que as práticas tradicionais possam ser usadas da forma correta, respeitando as leis ambientais e garantindo a conservação dos fragmentos florestais locais.

\section{AGRADECIMENTOS}

Os autores agradecem a Bruno Henrique Oliveira e Elaine Simonato Alves pelo auxílio nas coletas em campo. A Alexandre Quinet, Adriana Lobão, Mário Gomes e Ronaldo Marquete pelo auxílio na identificação de parte das espécies arbóreas. A Davi Nepomuceno da Silva Machado pelo auxílio com o diagrama de Venn e Letícia Rocha Caires pelos cálculos 
dos parâmetros fitossociológicos. À Universidade do Estado do Rio de Janeiro (SR-1) pelo apoio financeiro (bolsas de Estágio Interno Complementar e Iniciação à Docência CETREINA-UERJ).

\section{REFERÊNCIAS}

ADAMS, C. As roças e o manejo da Mata Atlântica pelos Caiçaras: uma revisão. Revista Interciência, v. 25, n. 3, p. 143-150, 2000.

APG IV - Angiosperm Program Group. An update of the angiosperm phylogeny classification for the orders and families of plants: APG IV. Botanical Journal of the Linnean Society, v. 181, p. 1-20, 2016.

BALÉE, W. Indigenous transformation of Amazonian forests: an example from Maranhão, Brazil. L'homme, v. 33, n. 2-4, p. 231-254, 1993.

BOND, W. J.; MIDGLEY, G. F. Ecology of sprouting in woody plants: the persistence niche. Trends in Ecology and Evolution, v. 16, p. 45-51, 2001.

BORGGARD, O. K.; GAFUR, A.; PETERSEN, L. Sustainability appraisal of shifting cultivation in the Chittagong Hill tracts of Bangladesh. AMBIO: J. Hum. Environ., v. 32, p. 118-123, 2003.

BRASIL. Decreto Federal n 750 , de 10 de fevereiro de 1993. Dispõe sobre o corte, a exploração de vegetação primária ou nos estágios avançados e médios de regeneração da Mata Atlântica, e dá outras providências. Diário Oficial [da] União, 11 de fevereiro de 1993. Seção I, p. 1801. Disponível em: https://www2.camara.leg.br/legin/fed/dec

ret/1993/decreto-750-10-fevereiro-1993-449133-publicacaooriginal-1-pe.html. Acesso em: 10 abr. 2020.

BRASIL. Lei Federal no 11.428, de 22 de dezembro de 2006. Dispõe sobre a utilização e proteção da vegetação nativa do Bioma Mata Atlântica, e dá outras providências. Diário Oficial [da] União, 26 de dezembro de 1993. Seção I. Retificado em 9 de janeiro de 2007. Disponível em: http://www.planalto.gov.br/ccivil_03/_Ato2004-2006/2006/Lei/L11428.htm. Acesso em: 15 abr. 2020.

CARVAlHO FILHO, A., LUMBRERAS, J. F., SANTOS, R. D. Os Solos do Estado do Rio de Janeiro. In: DANTAS, M. E. et al. Estudo geoambiental do gstado do Rio de Janeiro. 2. ed. Brasília: CPRM, 2000. CD-ROM (Anexos).

CATRY, F. X. et al. Post-fire tree mortality in mixed forests of central Portugal. Forest Ecology and Management, v. 206, p. 1184-1192, 2010.

CERDÀ, A.; LASANTA, T. Long-term erosional responses after fire in the Central Sapanish Pyrenees. Water and sediment yeld, Catena, v. 60, p. 59-80, 2005.

CERTINI, G. Fire effects on soil system functioning: new insights and future challenge. IJWF, v. 14, p. 339-342, 2005.

CHAZDON, R. L. Renascimento de florestas: regeneração na era do desmatamento. São Paulo: Oficina de Texto, 2016. 430 p.

CHIDUMAYO, E. N.; KWIBISA, L. Effects of deforestation on grass biomas and soil nutrientes satatus in miombo woodland, Zambia. Agriculture, Ecosystems and Environment, v. 96, n. 1, p. 97-105, 2003.

CHRISTENSEN, N. Succession and natural distrubance: paradigms, problems and preservation of natural ecosystems. In: AGEE, J. K.; JOHNSON, D. R. (org.). Ecosystem management for parks wilderness. Seatle: University of Washington Press, 1988. p. 62-86.

CONAMA - Conselho Nacional do Meio Ambiente. Resolução CONAMA nº 6, de 4 de maio de 1994. Estabelece definições e parâmetros mensuráveis para análise de sucessão ecológica da Mata Atlântica no estado do Rio de Janeiro Diário Oficial [da] União, de 30 de maio de 1994. n. 101, Seção I, p. 7913-7914. Disponível em: http://www2.mma.gov.br/port/conama/ legiabre.cfm?codlegi=147. Acesso em: 15 abr. 2020.

CPRM - SERVIÇO GEOLÓGICO DO BRASIL. Geologia e recursos minerais do estado do Rio de Janeiro: texto explicativo do mapa geológico e de recursos minerais. Belo horizonte: CPRM, 2016. Organizado por HEILBRON, M.; EIRADO, L. G.; ALMEIDA, J. 
DANTAS, M. E. Geomorfologia do estado do Rio de Janeiro. In: DANTAS, M. E. et al. Estudo geoambiental do estado do Rio de Janeiro. 2. ed. Brasília: CPRM, 2000. 63 p.

DEBANO, I. F. The role of fire and soil heating on water repellency in wildland environments: a review. Journal of Hydrology, v. 231-232, p. 195-206, 2000.

DISLICH, R.; CERSÓSIMO, L.; MANTOVANI, W. Análise da estrutura de fragmentos florestais no planalto paulistano, SP. Revista Brasileira de Botânica, v. 24, n. 3, p. 321-332, 2001.

DURIGAN, G. Métodos para análise de vegetação arbórea. In: CULLEN JUNIOR. L.; RUDRAN, R.; VALLADARES PADUA, C. (org.). Métodos de estudos em biologia da conservação e manejo da vida silvestre. Curitiba: Editora UFPR; Fundação O Boticário de Proteção à Natureza, 2003. p. 455-471. (Série Pesquisas, 88)

ERREA, M. P. et al. Soil moisture changes after land abandonment in the Central Spanish Pyrenees. Cuardernos de Investigación Geográfica, v. 27, p. 47-60, 2001.

FELFILI, J. M.; SILVA JÚNIOR, M. C. Distribuição dos diâmetros numa faixa de cerrado na Fazenda Água Limpa (FAL) em Brasília-DF. Acta Botanica Brasilica, v. 2, n. 1-2, p. 85-105, 1988.

FERNANDES, S. S. F.; PEREIRA, Z. V.; LOBTCHENKO, G. Estrutura e similaridade florística de dois componentes arbóreos de Florestas Estacionais Semidecíduas do Parque Estadual das Várzeas do Rio Ivinhema - MS. Ensaios e Ciência: Ciências Biológicas, Agrárias e da Saúde, v. 17, n. 6, p. 63-78, 2013.

FRIZANO, J. et al. Labile phosphorus in soils of forest fallows and primary forests in the Bragantine Region, Brazil. Biotropica, v. 35, p. 2-11, 2003.

GANDOLFI, S.; LEITÃO FILHO, H. F.; BEZERRA, C. L. Levantamento florístico e caráter sucessional das espécies arbustivo-arbóreas de uma Floresta Mesófila Semidecidual no município de Guarulhos, SP. Revista Brasileira de Biologia, v. 55, n. 4, p. 753-767, 1995.

GÓMEZ-POMPA, A.; WIECHERS, B. L. Regeneración de los ecosistemas tropicales y subtropicales. In: GOMÉZ-POMPA, A. et al. (org.). Investigaciones sobre la regeneración de selvas altas en Veracruz, México. México: Continental, 1976. p. $11-30$.

GOTELli, N. J.; ELLISON, A. M. Princípios de estatística para ecologia. Porto Alegre: Artmedm, 2016. 527 p.

GRINGS, M.; BRACK, P. Árvores na vegetação nativa de Nova Petrópolis, Rio Grande do Sul. Iheringia, Série Botânica, v. 64, n. 1, p. 5-22, 2009.

GUARATINI, M. T. G. et al. Composição florística da Reserva Municipal de Santa Genebra, Campinas, SP. Revista Brasileira de Botânica, v. 31, n. 2, p. 323-337, 2008.

GUARIGUATA, M. R.; OSTERTAG, R. Neotropical secondary forest succession: changes in structural and functional characteristics. Forest Ecology and Management, v. 148, n. 1, p. 185-206, 2001.

GUEDES BRUNI, R. R. et al. Inventário florístico. In: SYLVESTRE, L. S.; ROSA, M. M. T. (org.). Manual metodológico para estudos botânicos na Mata Atlântica. Seropédica: EDUR, 2002. p. 24-50.

GUEDES BRUNI, R. R.; LIMA, H. C. Serranias do estado do Rio de Janeiro: o conhecimento florístico atual e as implicações para a conservação da diversidade na Mata Atlântica. Eugeniana, n. 22, p. 9-22, 1996.

HEILBRON, M. et al. Brasiliano belts in SE Brazil. Journal of Virtual Explorer, v. 17, 2004. Disponível em: http://www.virtualexplorer.com.au/journal/ 2004/17. Acesso em: 10 abr. 2020.

IBGE - Instituto Brasileiro de Geografia e Estatística. Manual técnico da vegetação brasileira. 2. ed. Rio de Janeiro: IBGE, 2012. 246 p. (Manuais Técnicos em Geociências, 1).

JONHSON, C. M. et al. Carbon and nutrient storage in primary and secondary forests in eastern Amazonia. Forest Ecology and Management, v. 147, n. 2, p. 245-252, 2001.

KOTTEK, M. et al. World map of the Köppen-Geiger climate classification updated. Meteorologische Zeitschrift, v. 15, n. 3, p. 259-263, 2006. 
LAWRENCE, D. et al. Ecological feedbacks following deforestation create the potential for a catastrophic ecosystem shift in tropical dry forest. PNAS, v. 14, n. 5, 2007.

LIMA, H. C.; GUEDES-BRUNI, R. R. Diversidade de plantas vasculares na Reserva Ecológica de Macaé de Cima. In: LIMA, M. P. M.; GUEDES-BRUNI, R. R. (ed.). Serra de Macaé de Cima: diversidade florística e composição em Mata Atlântica. Rio de Janeiro: Instituto de Pesquisas Jardim Botânico do Rio de Janeiro, 1997. p. 29- 39.

LIMA, L. G. Influência do manejo agrícola na concentração de carbono e composição química da solução do solo em bioma de Mata Atlântica no distrito de São Pedro da Serra/Nova Friburgo. 2006. 148 f. Monografia (Licenciatura em Geografia) - Departamento de Geografia, Faculdade de Formação de Professores, Universidade Estadual do Rio de Janeiro, São Gonçalo, 2006.

LIMA, L. G. et al. Teor de carbono e nitrogênio total de solos com manejos diferentes em Bioma de Mata Atlântica na região serrana/RJ. In: SEMINÁRIO LATINO AMERICANO DE GEOGRAFIA FÍSICA, 4., 2006. Anais do... Maringá: Novos Paradigmas e Políticas Ambientais, 2006.

LIMA, H. C.; GUEDES BRUNI, R. R. Diversidade de plantas vasculares na Reserva Ecológica de Macaé de Cima. In: LIMA, M. P. M.; GUEDES BRUNI, R. R. (ed.). Serra de Macaé de Cima: diversidade florística e composição em Mata Atlântica. Rio de Janeiro: Instituto de Pesquisas Jardim Botânico do Rio de Janeiro, 1997. p. 29- 39.

LIMA, M. P. M.; GUEDES BRUNI, R. R. Reserva Ecológica de Macaé de Cima, Nova Friburgo -RJ: aspectos florísticos das espécies vasculares. Rio de Janeiro: Instituto de Pesquisas Jardim Botânico do Rio de Janeiro, 1996. v. 2. 465 p.

LINO, C. F.; ALBURQUERQUE, J. L.; DIAS, H. Mosaicos de unidades de conservação no corredor da Serra do Mar. São Paulo: Conselho Nacional da Reserva da Biosfera da Mata Atlântica, 2007. 96 p. (Cadernos da Reserva da Biosfera da Mata Atlântica, 1; Conservação e Áreas Protegidas, 32).

LPWG - The Legume Phylogeny Working Group. A new subfamily classification of the Leguminosae based on a taxonomically comprehensive phylogeny. Taxon, v. 66, n. 1, p. 44-77, 2017.

MAGALHÃES, L. M. S.; FREITAS, W. K. Fragmentos florestais em pequenas propriedades rurais: base para o seu manejo e conservação. In: CAMPELLO, E. F. C. (org.). Seminário sobre agricultura migratória na região serrana do Rio de Janeiro. Seropédica: EMBRAPA - Agrobiologia, 2004. p. 28-35.

MAGURRAN, A. E. Medindo a diversidade biológica. Curitiba: EDUFPR, 2013. 261 p.

MARMONTEL, C. V. F. et al. Caracterização da vegetação secundária do bioma Mata Atlântica com base em sua posição na paisagem. Bioscience Journal, v. 29, n. 6, p. 2042-2052, 2013.

MARTINELLI, G.; MORAES, M. D. Livro vermelho da flora do Brasil. 1. ed. Rio de Janeiro: Andrea Jakobsson; Jardim Botânico do Rio de Janeiro, 2013. 1100 p.

MARTINS, F. R. Estrutura de uma floresta mesófila. Campinas: UNICAMP, 1991. 246 p.

MATAIX-SOLERA, J. et al. Fire effects on soil aggregation: a review. Earth-Science Reviews, v. 109, p. 44-60, 2011.

MAtos, G. M. M.; FerRari, P. G.; CAVAlCANTE, J. C. Projeto Faixa Calcária Cordeiro / Cantagalo. Rio de Janeiro: CPRM, 1980. 622 p. v.1. Relatório final das minas e energia.

MORETT, A T.; MAYER, J. M. Questão ambiental em Nova Friburgo. In: ARAÚJO, J. R.; MAYER, J. M. Teia serrana: formação histórica de Nova Friburgo. Rio de Janeiro: Ao Livro Técnico. 2003.

NIGH, R.; DIEMONT, S. A. W. The Mya milpa: fire and the legacy of living soil. The Ecological Society of America Journal, v. 11, Online Special Issue: Prescribed burning, p. 45-54, 2013. Doi: 10.1890/120344.

OBALE-EBANGA, F. et al. Myths of slash and burn on physical degradation of savannah soils: impacts on vertisols in north Cameroon. Soil Use Manage, v. 19, p. 83-86, 2003.

OLIVEIRA FILHO, A. T. et al. Diversity and structure of the tree community of a fragment of tropical secondary forest of the Brazilian Atlantic Forest domain 15 and 40 years after logging. Revista Brasileira de Botânica, v. 27, n. 4, p. 685-701, 2004. 
OLIVEIRA FILHO, A. T.; FONTES, M. A. L. Patterns of floristic differentiation among atlantic forest in southeastern Brazil and influence of climate. Biotropica, v. 32, n. 4b, p. 793-810, 2000.

OLIVEIRA, J. R.; MANTOVANI, W.; MELO, M. M. R. F. Estrutura do componente arbustivo-arbóreo da Floresta Atlântica de encosta, Peruíbe, SP. Acta Botanica Brasilica, v. 15, n. 3, p. 391-412, 2001.

OLIVEIRA, R. R. Ação antrópica e resultantes sobre a estrutura e composição da Mata Atlântica na Ilha Grande, RJ. Rodriguésia, v. 53, n. 82, p. 33-58, 2002.

OLIVEIRA, R. R. Mata Atlântica, paleoterritórios e história ambiental. Ambiente \& Sociedade, v. 10, n. 2, p. 11-23, 2007.

OLIVEIRA, R. R. et al. A gênese estrutural de um paleo-território: a sucessão na Floresta Atlântica nos primeiros dez anos após uso por população caiçara. Pesquisas, Botânica, n. 59, p. 113-128, 2008.

PEDROSO JUNIOR, N. N.; MURRIETA, R. S. S.; ADAMS, C. A agricultura de corte e queima: um sistema em transformação. Boletim do Museu Paranaense Emilio Goeldi, Ciências Humanas, v. 3, n. 2, p 153-174, 2008.

PEIXOTO, A. L.; MAIA, L. C. Manual de procedimentos para herbários. INCT. Herbário virtual para a flora e os fungos Recife: Universitária UFPE, 2013. 102 p.

PENHA, A. S. Propagação vegetativa de espécies arbóreas a partir de raízes gemíferas: representatividade na estrutura fitossociológica e descrição dos padrões de rebrota de uma comunidade florestal, Campinas, São Paulo. 1988. 188 f. Tese (Doutorado em Ecologia) - Instituto de Biologia, Universidade Estadual de Campinas, Campinas - SP, 1988.

PÉREZ-CABELLO, F. et al. Alteraciones edáficas en comunidades vegetales quemadas 15 años tras el fuego. In: BIENES, R. Y; MARQUÉS, M. J. (ed.). Control de la erosión y degradación del suelo. Madrid, 2003. p. 211-214.

PESSOA, S. V. A.; GUEDES BRUNI, R. R.; KURTZ, B. C. Composição florística e estrutura do componente arbustivo-arbóreo de um trecho secundário de Floresta Montana na Reserva Ecológica de Macaé de Cima. In: LIMA, H. C.; GUEDES BRUNI, R. R. (ed.). Serra de Macaé de Cima: diversidade florística e conservação em Mata Atlântica. Rio de Janeiro: Instituto de Pesquisas Jardim Botânico do Rio de Janeiro, 1997. p. 147-167.

REFLORA - Plantas do Brasil: Resgate Histórico e Herbário Virtual para o Conhecimento e Conservação da Flora Brasileira. Flora do Brasil 2020. Rio de Janeiro: Fundação Instituto de Pesquisas Instituto de Jardim Botânico do Rio de Janeiro, 2020. [Site]. Disponível em: http://floradobrasil.jbrj.gov.br/. Acesso em: 20 jan. 2021.

REFLORA. Herbário virtual. Fundação Instituto de Pesquisas Jardim Botânico do Rio de Janeiro. [Site]. Disponível em: http://www.jbrj.gov.br/jabot. Acesso em: 10 jan. 2021.

RIO DE JANEIRO (Estado). Decreto Lei Estadual n0. 29.213, de 14 de setembro de 2001. Dispõe sobre a criação da Área de Proteção Ambiental de Macaé de Cima (APA de Macaé de Cima) no município de Nova Friburgo e dá outras providências. Diário Oficial [do] Estado do Rio de Janeiro, 17 de setembro de 2001. Parte I - Poder Executivo, p. 25. Disponível em: http://www.pesquisaatosdoexecutivo.rj.gov.br/Home /Detalhe/30156. Acesso em: 10 abr. 2020.

RODERJAN, C. V., KUNIYOSHI, Y. S. Macrozoneamento florístico da Área de Proteção Ambiental Guaraqueçaba. Curitiba: FUPEF, 1988. (Série Técnica, 15).

SANCHEZ, M. et al. Composição florística de um trecho de floresta ripária na Mata Atlântica em Picinguaba, Ubatuba, SP. Revista Brasileira de Botânica, v. 22, n. 1, p. 31-42. 1999.

SANCHEZ, P. A. et al. Alternatives slash-and-burn: challenge and approaches of an international consortium. In: PALM, C. A. et al. (org.). Slah-and-burn agriculture: the search for alternatives. New York: Columbia University Press. 2005.

SHEPHERD, G. J. FITOPAC 2.1. Campinas: UNICAMP, 2009. 93 p.

SILVA, A. P. B. Influência do pousio nas propriedades físicas e químicas dos solos em Bioma de Mata Atlântica: o caso de São Pedro da Serra - Nova Friburgo. 2005. 156 f. Monografia (Licenciatura em Geografia) - Departamento de Geografia, Faculdade de Formação de Professores, Universidade Estadual do Rio de Janeiro, São Gonçalo, 2005. 
SILVA, D. B. Fitossociologia do fragmento de Mata Atlântica da Fazenda Bela Vista em Nova Friburgo/RJ. 2009. 33 f. Trabalho de Conclusão de Curso (Graduação em Engenharia Florestal) - Instituto de Florestas, Departamento de Silvicultura, Universidade Federal Rural do Rio de Janeiro. Seropédica, 2009.

SPIEGEL, M. P. Estadística, teoría y problemas resueltos. Mexico: McGraw-Hill, 1970. 357 p.

STYGER, E. R. et al. Influence of slash-and-burn farming practices on fallow succession and land degradation in the rainforest region of Madagascar. Agriculture, Ecosystems e Environment, v. 119, n. 3-4, p. 257-269, 2007.

SZTUTMAN, M.; RODRIGUES, R. R. O mosaico vegetacional numa área de floresta contínua da planície litorânea, Parque Estadual da Campina do Encantado, Pariquera-Açu, SP. Revista Brasileira de Botânica, v. 25, n. 2, p.161-176, 2002.

TABARELLI, M.; MANTOVANI, W. A regeneração de uma floresta tropical montana após corte e queima (São Paulo-Brasil). Revista Brasileira de Biologia, v. 59, p. 239-250, 1999.

THOMAZ, E. L. Slash-and-burn agriculture: establishing scenarios of runoff and soil loss for a Five-year cycle. Agriculture, Ecosystems and Environment, v. 168, p. 1-6, 2013.

VELOSO, H. P. et al. Classificação da vegetação brasileira adaptada a um sistema universal. Rio de Janeiro: IBGE, 1991. $124 \mathrm{p}$.

VUONO, Y. S. Inventário fitossociológico. In: SYLVESTRE, L. S.; ROSA, M. M. T. (org.). Manual metodológico para estudos botânicos na Mata Atlântica. Seropédica: EDUR, 2002. p. 51-65.

\section{COMO CITAR ESTE TRABALHO}

Costa, K.K.S; Bertolino, A.V.F.A \& Barros, A.A.M. Regeneração da cobertura vegetal em área de agricultura de corte e queima em São Pedro da Serra, Nova Friburgo (Rio de Janeiro, Brasil) . Revista Tamoios, São Gonçalo, v. 17, n. 2, p. 84-110, 2021. Disponível em: https://doi.org/10.12957/tamoios.2021.58517. Acesso em: DD MM. AAAA. 